\title{
Article
}

\section{Ecopolitana: a plan of cities, territory, landscape and ecology}

\author{
Luca Del Fabbro Machado ${ }^{1}$, Adriano Venudo ${ }^{2 *}$, Alfredo Atobelli ${ }^{3}$, Jennifer Bertuzzi ${ }^{4}$, Francesca Zampieri ${ }^{5}$ and \\ Angela Gatti ${ }^{6}$
}

1 Department of Engineering and Architecture, University of Trieste, 34127, Trieste, Italy; luca.delfabbromachado@dia.units.it

2 Department of Engineering and Architecture, University of Trieste, 34127, Trieste, Italy; avenudo@units.it

3 Department of Life Sciences, University of Trieste, 34127, Trieste, Italy; altobell@units.it

4 Department of Life Sciences, University of Trieste, 34127; bertuzzijennifer95@virgilio.it

5 Department of Life Sciences, University of Trieste, 34127; francesca.zampieri00@gmail.com

6 Department of Life Sciences, University of Trieste, 34127; a.gatti@studioforst.it

* Correspondence: avenudo@units.it, luca.delfabbromachado@dia.units.it

\begin{abstract}
:
A national green planning strategy has recently been introduced in the Italian urban planning sector, aimed at making all local initiatives undertaken nationwide consistent with each other. At a regional level, Friuli Venezia-Giulia has recently implemented a Landscaping Plan, which is of an urban planning and ecological nature at an intermediate level between national and local. This article describes the local green plan of Latisana, which has been entitled Ecopolitana, given that it is represents the experimental phase, at a regional level, of the possibilities offered by landscape planning and design. Specifically, it outlines the multi-disciplinary approach used, demonstrating how landscape planning can be compared to the sustainable development of cities, with specific regard to the agricultural sector.

Regarding the agricultural sector, a low-intensity cropping model is also suggested, based on the principles of agroecology and landscape ecology, which has already been implemented in the historical rural landscape of Plasencis (UD) and developed through GIS analysis and remote sensing processes. Its aim is to be the starting point for the achievement of the goals set in the 2030 Agenda, and especially Goals 13 (Climate action) and 15 (Life on land), given the current scarcity of agroecological infrastructures in the area of Latisana (UD) and the high percentage of soil used for intensive cropping.
\end{abstract}

Keywords: ecopolitana; greenscape; forestry plan; ecological network; green infrastructures; biodiversity; agroecology; conservation agricolture; Sentinel 2; LiDAR. 


\section{Introduction}

The article describes the recently approved Local Green Plan (LGP) of the Municipality of Latisana, in Friuli Venezia-Giulia (Italy), and outlines its innovative role in territorial and landscape planning. The preparation of the LGP involved an exploratory project procedure, introducing into territorial and landscape planning in Italy a series of proposals and experimental tools aimed at achieving synergy between the ecological aspects and those of a social, spatial, perceptive and economic nature that are typically involved in urban planning. In brief, it was based on an approach that could be defined as "planning with nature".

This approach is also the result of a multi-disciplinary process involving individuals from various professional and academic backgrounds. The planning group was trained by professionals and included an urban planning architect, an agronomist, a landscaper and a geologist. The work was coordinated and supported by a group from the University of Trieste, coordinated by Professor Adriano Venudo (an architect), and composed of Professor Alessandra Marin (an urban planning architect) and Professor Alfredo Altobelli (a geologist).

The process of preparing the LGP, which was done in coordination with the local administration of the municipality of Latisana, in the person of the Urban Planning Assessor Luca Abriola, included a participatory phase involving the local people through a series of active listening initiatives, a workshop with the students of the faculty of architecture of the University of Trieste, a display of the projects and the publication of an instant book: Laboratorio Paesaggio Latisana [1].

In Italy, there is no legislation for defining and implementing green plans. They respond to the guidelines of the Ministry of the Environment and Land and Maritime Protection (MATTM), which define a series of methods of constructing the plans from a strategic viewpoint, at an overall national level, but the local territorial authorities are responsible for translating them into urban plans [2]. In brief, a green plan should be composed of three parts: a cognitive overview, an orientation plan and the technical legislation for implementation.

Friuli Venezia-Giulia is a region with a special statute, and is therefore independent in terms of urban planning legislation; the work on the Latisana (UD) PCV was started in January 2019. At that time, no municipality in Friuli Venezia-Giulia had a complete threepart green plan in place. The lack of a specific implementing legislation and the absence of a series of comparable experiences at a regional level therefore made this tool a new one, with an exploratory role, the structure of which is described in the following section.

An Urban Green Plan is defined by the MATTM as an extraordinary tool which, in addition to providing a strategic overview of the (semi)natural, agro-forestry, urban and hinterland layout of the city, also defines the principles and establishes the orientation criteria for the realisation of public green areas in the framework of future general urban planning [3].

This study broadens the definition in such a manner as to comprehend all of the questions contemplated in the general conception of a LGP and contributes towards planning. In brief, the PCV is intended as being a planning tool which provides a strategic vision of the natural and anthropic systems of the landscape and defines the principles for the realisation of green areas, with the following objectives: mitigating the environmental impact of anthropic activity in the area, guaranteeing a more rational use of the environmental resources, valorising the farming land, optimising the social, aesthetic and environmental role of open spaces in and around cities and encouraging the economic and social development of the area.

This type of plan is a recent addition to the planning sector aimed at achieving environmental and social sustainability, with specific reference to the 17 Global Goals For Sustainable Development [4] adopted by the UN in 2015 and aimed at solving a series of criticalities by 2030. In particular, landscape and territorial planning, as in the definition 
being used in this instance, is directly comparable to Goals 11 (Sustainable cities and communities), 15 (Life on Land) and, indirectly, Goal 13 (Climate action).

In line with that stated in Goal 11, it is generally believed that the management of urban and extra-urban green areas must be conjoint. Currently, rural areas are asked not only to deal with primary production, but also numerous other ecosystem services combining the supply of food with the production of landscape and nature [5].

On the basis of these presuppositions, it has been decided to analyse a portion of the farming mosaic on the municipality of Latisana, together with the PCV, and suggest a low-intensity cultural model based on the principles of agroecology [6] and landscape ecology [7]. Conservation agriculture is a recent soil management technique based on the reduction of processing (minimum or no tillage), maintaining a continuous covering of the land with residual crops and/or cover crops and crop rotation [8]. This technique helps not only to mitigate the problem of soil erosion but also promotes the efficient use of water and nutrients, the quality of the soil, the sustainability of farming and its products and, especially, encourages biodiversity [9]. Friuli currently has 9,813 hectares of seeded land managed sustainably, of which $21 \%$ is used for conservation agriculture.

As regards landscape ecology, we believe that the presence of adequate farming and ecological infrastructures capable of increasing functional biodiversity to provide ecosystem services is extremely important, given the characteristics of the area being surveyed.

This detailed study has the objective of investigating the sustainable management of soil in the presence of farming and ecological infrastructures in the countryside of Latisana with respect to that of Plasencis and to suggest a strategy for analysing them using GIS and remote sensing systems. Plasencis is one of the five hamlets in the municipality of Mereto di Tomba (Udine). It is located on the Friuli high plain to the south of the moraine range of hills. It is an area rich in farming and ecological infrastructures and closed fields making the farming ecosystem ideal for hosting high levels of biodiversity. This, and the sustainable farming practices implemented in this area, is why Plasencis has been chosen as a model of sustainability to compare to Latisana.

\section{Materials and Methods}

\section{A territory of soil and water}

The Latisana green plan is structured as follows:

Cognitive overview

Strategic part

Operative part

The cognitive overview is the result of the analyses, readings, interpretations, surveys and feedback of the inter-disciplinary work group in the area. It is aimed at understanding and interpreting the landscaping and environmental aspects of the area, the landscape being intended as an exterior manifestation "of the overall organisation of an area»[10]. The outcome is a planning basis aimed at the identification of a complex spatial structure on which to base the strategies and actions of the plan. From a methodological viewpoint, the cognitive overview is the result of different interpretative approaches. Knowledge of the area from the various disciplinary aspects is achieved through in-the-field surveys (inspections), mapping research and remote sensing, as described later on. An interpretative and preparatory phase to the plan involved an educational and research course involving the students from the Laboratory of integrated planning of the city, landscape and surrounding area of the University of Trieste. Through the planning laboratory, an educational workshop on the area being surveyed and a display of the projects, the principle of the plan as a tool for knowledge was used. This enabled the start of a participative phase with the local people, involving an exhibition of 
the students' work, visioning sessions, topical focus groups and conferences open to all on the topics of ecology, agriculture and landscape planning.

The strategic part lays down the ideas for the future of the landscape through a series of choices, orientations and principles, constructing an overall vision for the area. This emerges directly from the cognitive overview and has the role of integrating the Green Plan with regional plans, in particular the Regional Landscaping Plan, and local tools, such as the general Local Regulatory Plan, the General Urban Traffic Plan, the Rural Police Regulation and the Construction Regulation.

The operative part is the translation of the vision suggested in the strategic part into rules and zoning and is constituted by the contexts of the plan and a green regulation, which dictates the rules for the management, transformation, planning and protection of the local green areas.

As already mentioned, the essence of the plan is closely based on the cognitive framework. The first in-the-field definition of construction of this framework is the identification of the Landscape Unit (LU), this being intended as the landscape subsystem characterised spatially by the ecosystems that comprise it, the delimitation of which coincides with the presence of historical and geographical elements, historical and morphological aspects and the distribution of vegetation, consistently with Vittorio Ingegnoli's definition of landscape [11]. The municipality of Latisana is part of a wider ranging context, a sub-region, which has overall characters linked to the geography and morphology of the area and the landscape, and which mainly includes the Friuli lower plain and the coastline and lagoon. The reference Landscape Unit for the construction of the cognitive overview goes beyond the administrative confines of the Municipality of Latisana and is identified as follows (Figure 1).

- The rivers (to the East and West): the reference area is accurately delimited by two major rivers, the Tagliamento and Stella, which are almost parallel, the distance separating them varying from about 5 to 7 kilometres, where there is a single portion of soil with consistent characteristics. In addition to having a vital role in shaping the morphology and in the perceived landscape, these two elements also contain most of the natural resources in the area (with an ecological connectivity function).

- The infrastructural area (to the North): the main roads and railways (the A4 highway, State Road no. 14 and the Venice-Trieste railway line) which run from West to East in the area in question, passing to the north of Latisana and forming a cordon which significantly delimits the landscape, acting as a barrier as well a major anthropic element.

- The lagoon (to the South-East): the Lagoon of Marano and Grado extends mainly on the outside of the reference area, but its presence clearly delimits the area of Latisana and its extension to the river Stella. The lagoon is not only a bordering element: it must be pointed out that the origin of the area itself, which in ancient times was swampland, has determined over time the current state of the soils as a result of an anthropic action closely linked to the presence of the lagoon and the swampy nature of the surrounds; the LU is mainly a land reclamation area.

- The Veneto coastline (to the South): an element that is in itself minor in the context described until now, the artificial channel of the Veneto coastline runs between the municipalities of Latisana and Lignano Sabbiadoro. It is a linear element of anthropic origin, but with an ecological function, as it is connected to the river Tagliamento on one side and the Lagoon of Marano and Grado on the other. 


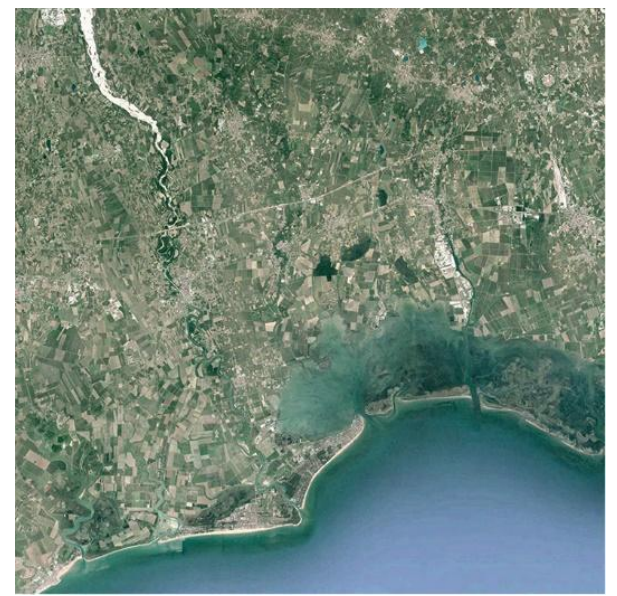

(a)

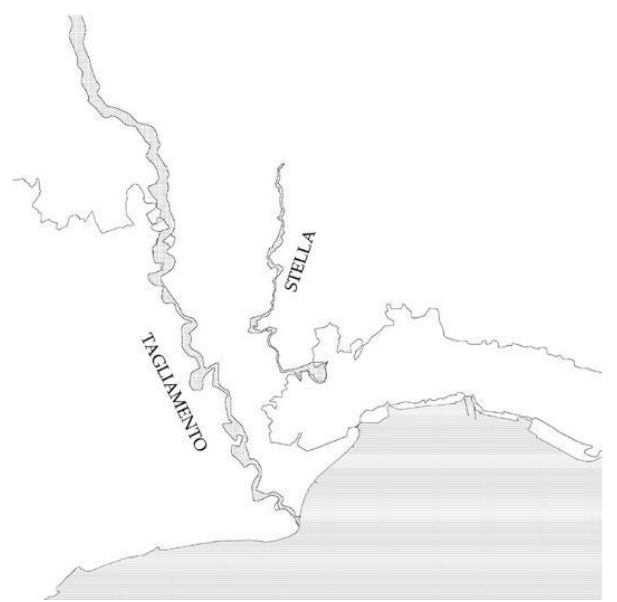

(c)

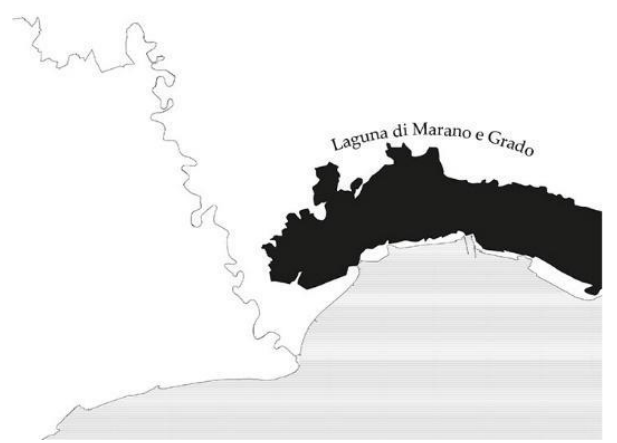

(e)

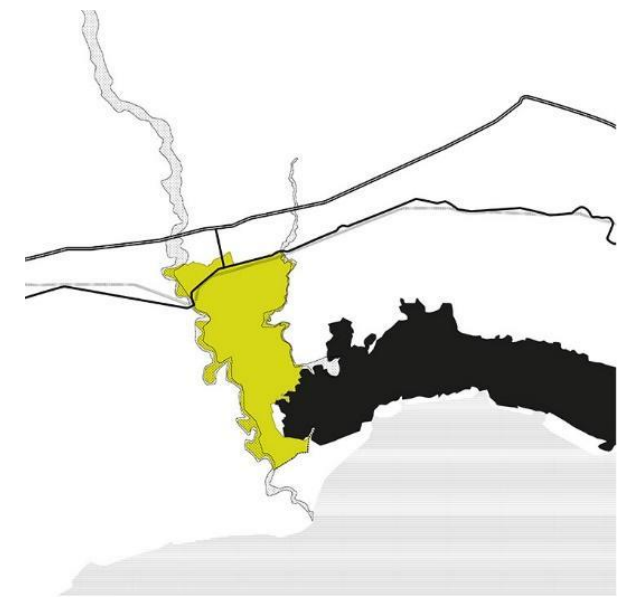

(b)

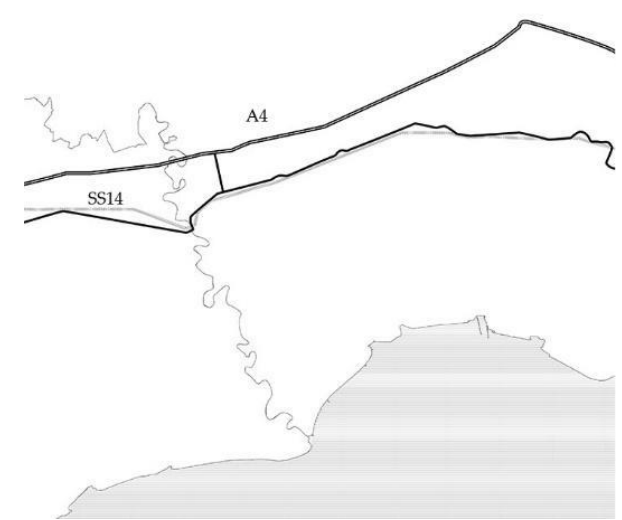

(d)

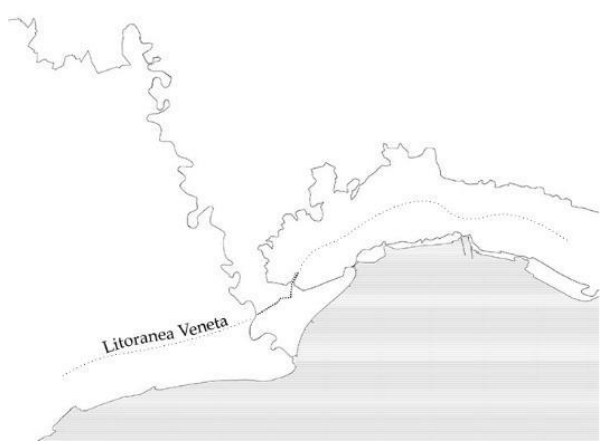

$(\mathbf{f})$

Figure 1. The Landscape Unit: a) Orthophoto overview b) the components of the LU; c) Tagliamento and Stella rivers; d) the infrastructural area; e) the Lagoon of Marano and Grado; f) the Veneto coastal channel

The Landscape Unit involved in the overall landscape analysis - and also the planning strategies of the Green Plan itself - is therefore an area that also includes part of the two Municipalities bordering it to the East and North. The total surface area of the LU is approximately $64.88 \mathrm{~km}^{2}$. 
The results of the analysis are the basis used to identify the system of landscapes and the configuration of the local ecological network. Specifically, two landscape matrices have been identified, originating from the peculiar mix of the morphological structure, the vegetation present (indigenous and non-indigenous species present) and the history and evolution of the area: the farming matrix and the hydrographic matrix.

\section{Farming matrix (Figure 2):}

The area of the municipality of Latisana has undergone significant transformations over time, simultaneously to the evolution of the needs and methods of farming the land for production and food purposes. There is a profound and historical relationship between the forms of urbanisation and extent of the settlements (for example by hamlets) and the forms of cultivating the land. The various land reclamations over time have definitively transformed the land and naturalistic aspects, structuring the entire area as it is today on the basis of farming activity. Stretches of farms, the viability layout, the settlement bases, construction types and especially the species of trees and plants currently present in the area are the result of stratification over time of the practices of farmland management and usage of the countryside that are still visible in the area, and also in cartography.

According to a measurement made on the Charter of Habitats of the Friuli VeneziaGiulia region in 2017, the farming areas, including allotments in the urban areas, vines, fruits and Populus plantations, excluding the fishing valley, cover a total surface area of approximately $52 \mathrm{~km}^{2}$, equivalent to more than $80 \%$ of the total surface area of the LU. Of this, the vast majority is constituted by intensively seeded land, with a minor part being fruit crops and vines.

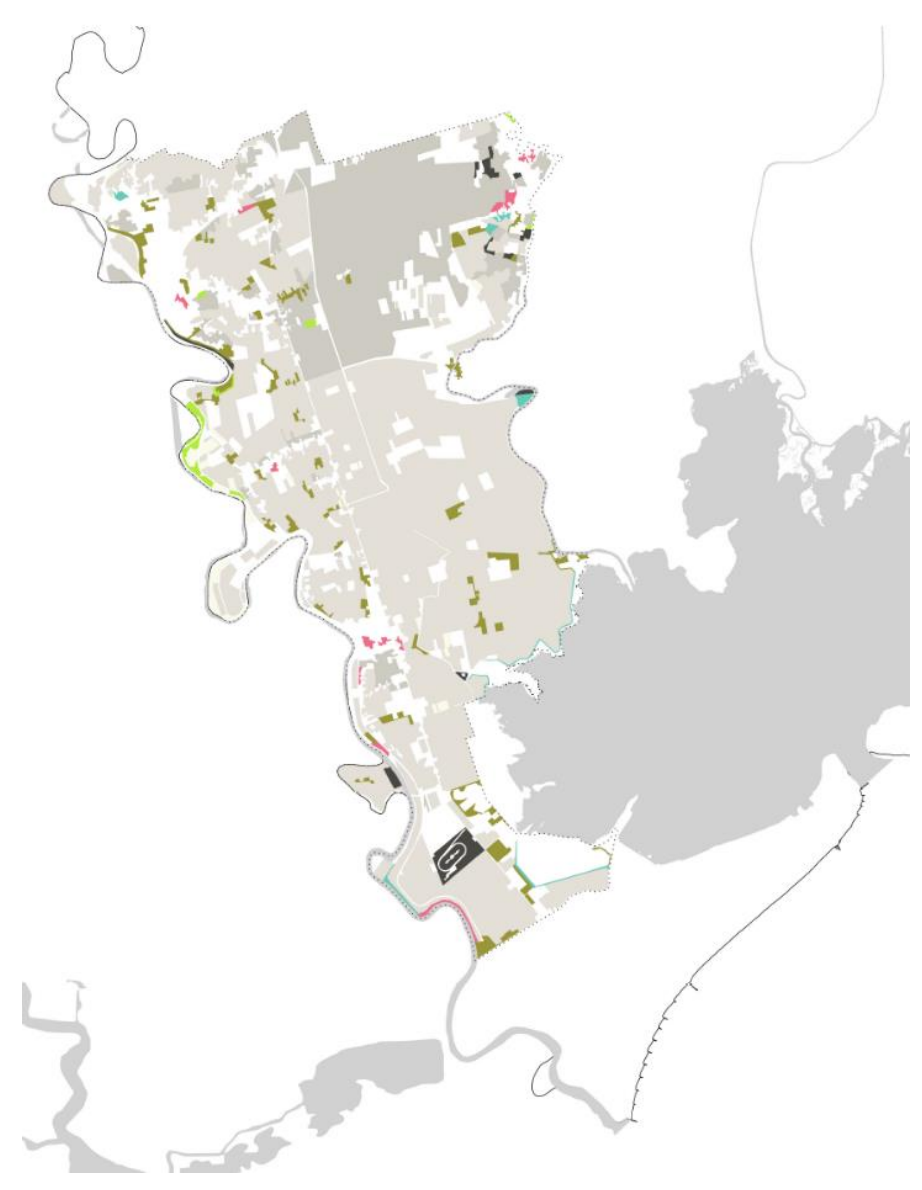

Figure 2. Location of farming areas in the LU 
The assessment of the farming matrix of the LU was conducted by comparing two sample areas covering $7 \mathrm{~km}^{2}$, one of them in the municipalities of Latisana and Precenicco, within the Landscape Unit described above (Figure 4), and the other located in the "Plasencis countryside" between the municipalities of Mereto di Tomba, San Vito di Fagagna and Coseano (Figure 3).

The latter is part of the National Rural Network, given that it is considered to be historical rural landscape. The significance of the area is linked to the persistence of a landscape mosaic of closed fields (shelter belts), delimited by hedges and rows of trees (Figures 3.4, 3.7, 3.9 and 3.10). This peculiarity represents one of the main characteristics of the historical farming landscape of the Friuli plains. Contrarily to what has occurred in the remainder of the areas, the area selected has not yet undergone land reordering interventions, which have modified the farming areas with a view to improving production yields. The fields in the area are still divided by common oak, ash, maple, false acacia and elderberry trees, also used to delimit their confines, and rows of mulberry bushes (Figure 3.3), introduced in the late eighteenth century with the widespread introduction of sericulture [12]. The spaces thus delimited, closed or semi-closed, include arable land and pastures. Some of the farmed fields are used for conventional agriculture, and there is also a widespread use of conservative agriculture.
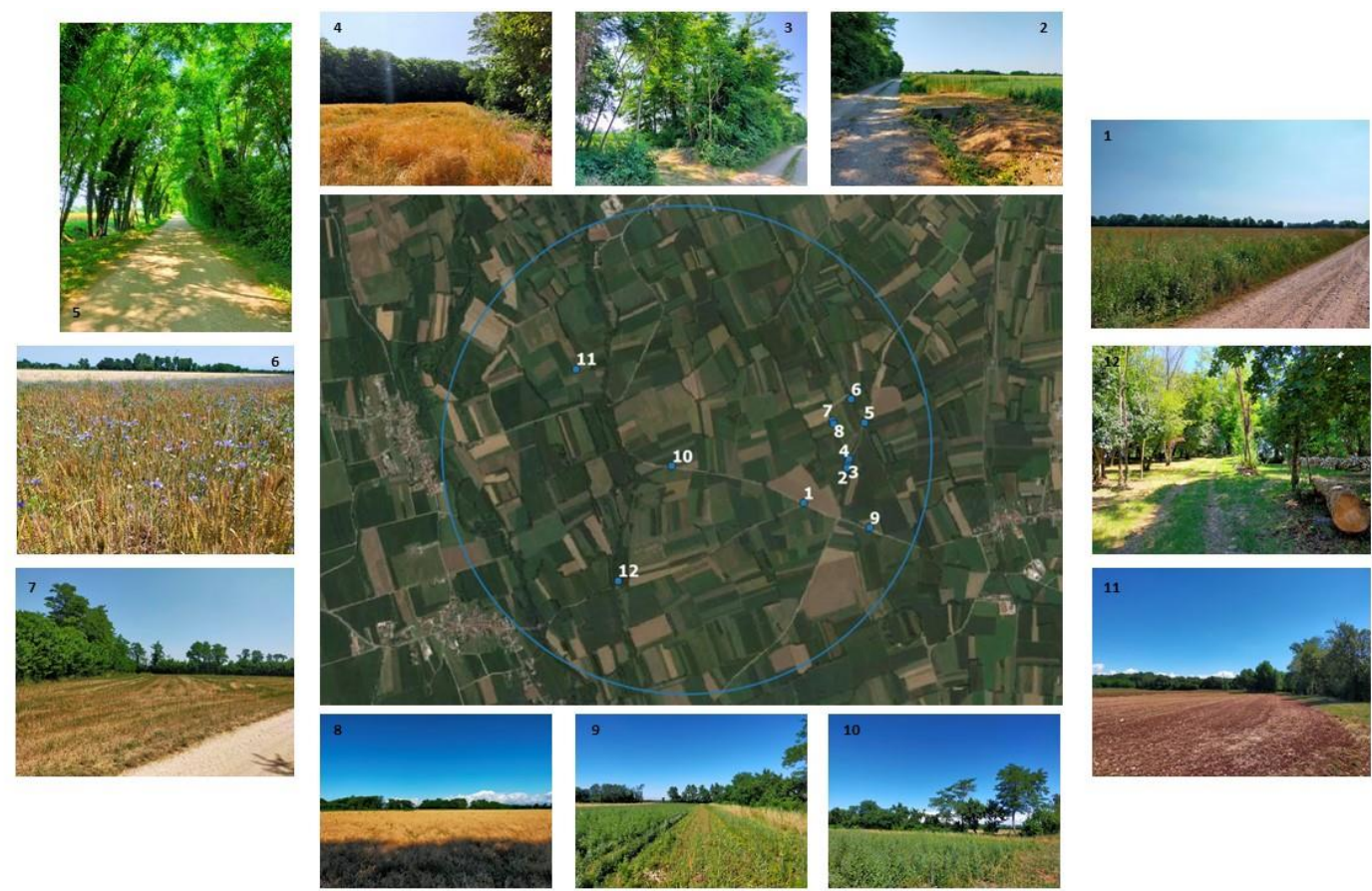

Figure 3. Graphic contextualisation of the sample area in the Plasencis countryside. The numbered photos, the position of which is given in the superimposed polygon, showing a selection of the variety of linear and punctual elements of the landscape such as [1]

[3] [8] rows of trees, [2] ditches, [4] [7] [9] [10] protective belts, [11] [12] groves and [6] permanent grassland.

On the other hand, the countryside around Latisana only has land that is farmed conventionally and intensively. As can be seen in Figure 4, and specifically in images 4.1 and 4.6, the conformation of closed fields typical of Plasencis gives way here to open hectares of land with almost no linear structure or markers which, if present, are natural remains from past ages. 

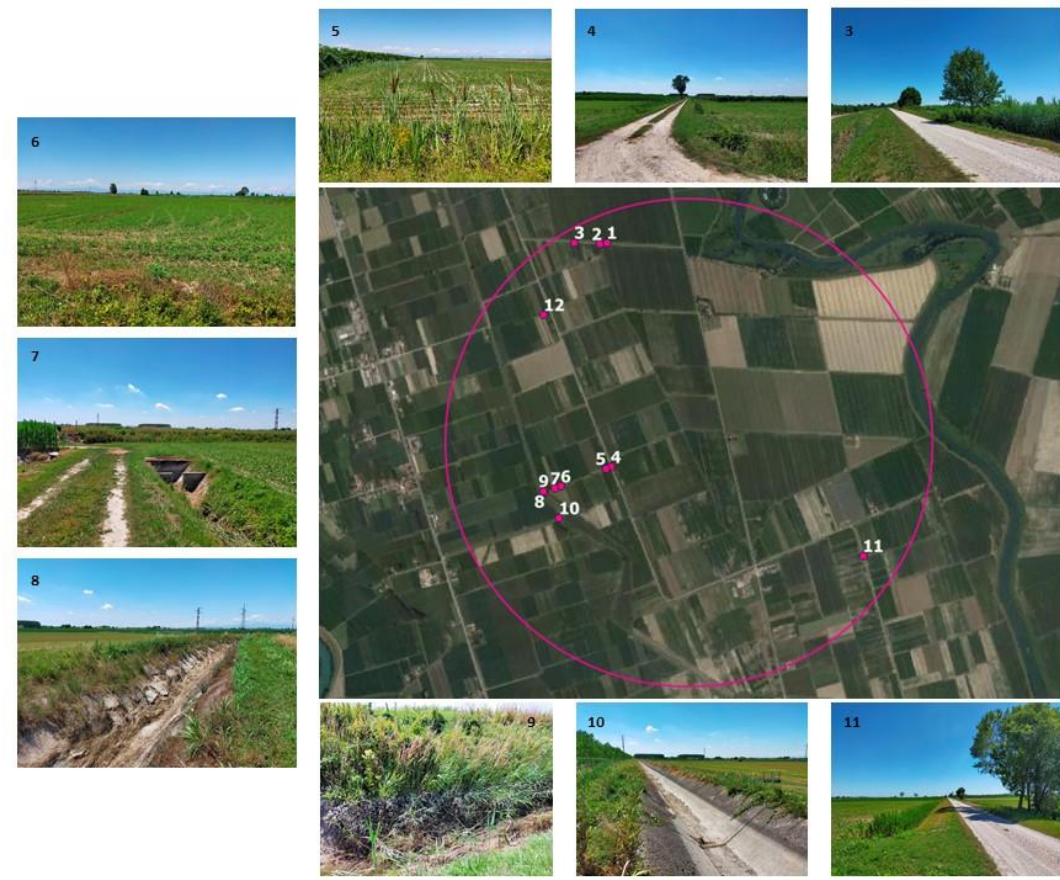

Figure 4. Graphic contextualisation of the sample area in the Latisana countryside. The numbered photos, the position of which is given in the superimposed polygon, showing a selection of the variety of linear, spatial and punctual elements of the landscape such as [1] [2] [7] ditches, [3] [4] [6] [11] individual trees, [5] Typha latifolia, [8] Fossalon canal, [9] grassy vegetation in the Fossalon canal, [10] artificial canal and [12] vines interspersed with threshed wheat.

The two sample areas were compared taking two environmental parameters into account: the presence of linear vegetation elements [13] (hedgerows, field margins, buffer strip, shelterbells) and punctual ones (stepping stones) (small structures such as groves, ponds, etc.), and the extent of the practice of conservative agriculture, to define the sustainability of the cropping practices present.

The mapping of the linear and punctual agroecological infrastructures and the identification of the conservative agriculture areas was done using GIS and remote sensing techniques. A very interesting opportunity is the increasing availability of LiDAR (Light Detection and Ranging) high-resolution remotely detected data, which enables a three-dimensional representation of vegetation infrastructures to be obtained. In these analyses, LiDAR data freely accessible through the IRDAT-FVG infrastructure (https://eaglefvg.regione.fvg.it) from 27 March 2018 was used. For calculating the density of these infrastructures, the intensity values provided by the LIDAR images through open source CloudCompare software were interpreted.

For the identification of the areas used for conservative agriculture, we based our findings on optical remote sensing, making use of one of the fundamental characteristics of this cropping technique, in other words maintaining a permanent soil cover which enables the fields managed conventionally to be distinguished from those managed conservatively.

The methodology used is based on the spectral response of the soil and vegetation in visible or infrared wavelengths. These were then analysed using a temporal series (October 2020 - July 2021) from the index Normalized Difference Vegetation Index [14] calculated from Sentinel-2 L2A satellite images. The index is characterised by values close to zero for bare soil, which increase in areas with a residual presence of crops and proportionately to the photosynthetically active biomass present.

All of the data processing was done using free and open source GIS software (QGIS, SNAP, Google Earth Engine and CloudCompare).

Hydrographic matrix (Figure 5): 
The local area has deep roots, detectable in the structure itself, with water, which has a technical role (discharge and irrigation), a historical and testimonial role (the settlement and port origin of all of the inhabited centres along the river Tagliamento) and a landscape value (the riparian corridor of the Tagliamento and the lagoon embankment). The river Tagliamento, the Marano lagoon, the Veneto coastal canal and the complex network of natural canals and artificial canals resulting from land reclamation are the main environmental and landscaping framework characterising the layout of the land, and specifically the form, structure and especially the settlement origins of the main town (Latisana) and also of all of its hamlets (Pertegada, Gorgo, Bevazzana), including those of more recent construction (Aprili Marittima and Latisana Marittima). The hydrographic network, which has literally designed the urban layout of the Municipality of Latisana, is also one of the main supply of natural resources in the area.

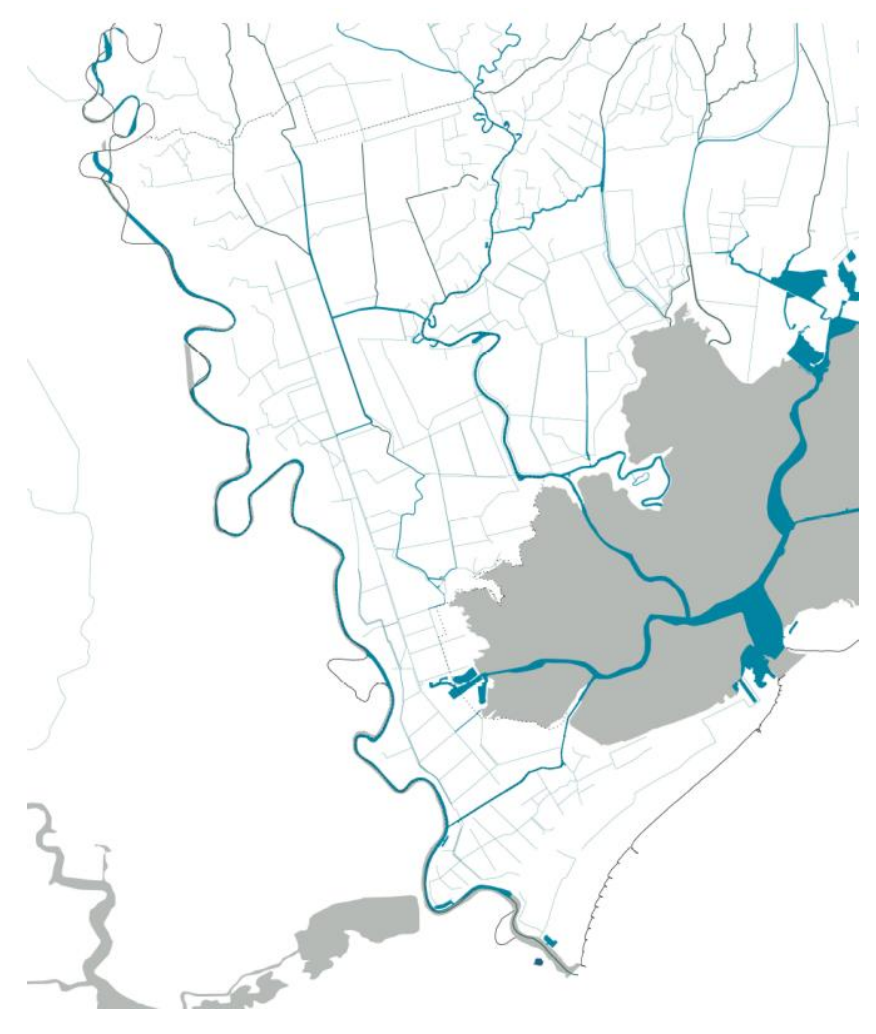

Figure 5. The hydrographic network

The landscaping analysis of the area includes the analysis of the physical landscaping units, defined as forms or complexes of forms of the land to which specific geological processes and mechanical, geotechnical, soil and optimal use characteristics can be attributed.

By adopting a hierarchical approach, the Physical Landscape Macro units of a local nature can be identified: these are areas that are consistent from the viewpoint of the morphological and evolutionary process that distinguish one from the other by the scale of the local area.

When the conditions are in place for further subdivisions to be made (such as in this case and the Latisana area) within a Macro unit, the Physical Landscape Meso units of a "sub-local" range are identified. The Physical Landscape Micro units are then identified within the Macro units and the Meso units, which are specific individual morphological sculptures (the riverbed, a floodplain, fragments of countryside, etc.). These are the physical landscape elements of a minor hierarchical value that do not necessarily cover a wide area.

The LGP characterises the LU as follows: 
1. The Landscape Unit of the Latisana farming and river areas

Four Landscape Sub-Units (LSU) have been identified within the LU, on the basis of the two landscaping matrices of the area around Latisana:

1.1 Paesaggio Fluviale

1.2 Paesaggio dell'Agro Urbano Latisanese

1.3 Paesaggio della Bonifica

1.4 Paesaggio della Laguna

Within each of the Landscape Sub-Units, the Landscape Cells (LC) are identified on the basis of the punctual nature of the soil layout, the place names, plant species and characteristics of the settlement systems, as specific declinations of the homogeneous characteristics of the landscape matrices within the 4 LSU. The Landscape Cells are (Figure 6):

$\begin{array}{ll}\text { 1.1.1 } & \text { Paesaggio arginale } \\ \text { 1.1.2 } & \text { Anse della Mucola } \\ \text { 1.1.3 } & \text { Anse della Voltuzza } \\ \text { 1.1.4 } & \text { Ansa della Volta } \\ \text { 1.1.5 } & \text { Ansa dei Picchi } \\ \text { 1.1.6 } & \text { Ansa della Valle Pantani } \\ \text { 1.1.7 } & \text { Sacca dell' Alzaia } \\ \text { 1.2.1 } & \text { Selva } \\ \text { 1.2.2 } & \text { Beorchia - Pra di Coi } \\ \text { 1.2.3 } & \text { Rotta } \\ \text { 1.2.4 } & \text { Gorgo } \\ \text { 1.2.5 } & \text { Pertegada } \\ \text { 1.2.6 } & \text { Picchi } \\ \text { 1.3.1 } & \text { Prati di Latisana } \\ \text { 1.3.2 } & \text { Picchi } \\ \text { 1.3.3 } & \text { Valle Pantani } \\ \text { 1.4.1 } & \text { Valle Pantani }\end{array}$

The strategic part, and also the implementation of the LGP, is based on this summary mosaic, which has the objective of becoming the basic support for the contextualisation of the detailed planning of the various interventions envisaged by the LGP.

Figure 6. Municipality of Latisana, identifying the Landscape Sub-Units and the Landscape Cells 


\section{Results}

\section{Ecopolitana}

The plan's general idea, Ecopolitana is based on a figure, that is both, vision of transformation and process, as well as hypothesis of structure and territory framework (Figure 7). It is a concept whose objective is the construction of a layout that integrates the urban-infrastructural dimension with the landscape-environmental one "Using principles is not difficult, and leads to more integrative designs and plans. It helps reduce the landscape fragmentation and degradation so evident around us." [15]

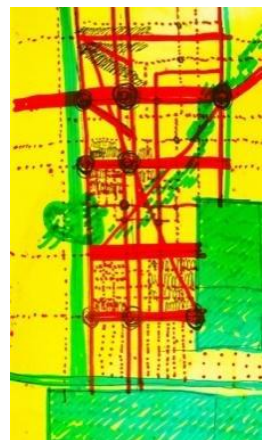

(a)

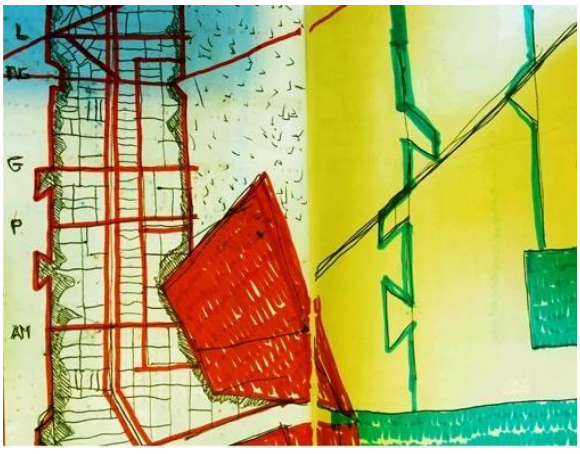

(b)

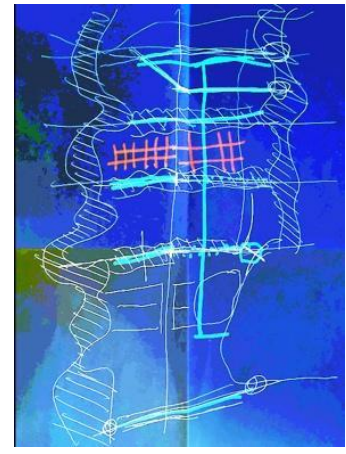

(c)

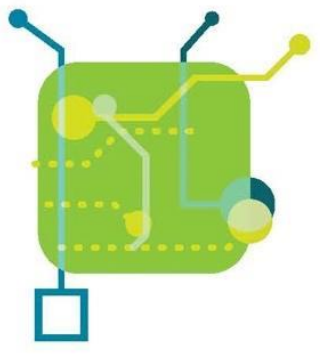

(d)

Figure 7. Ecopolitana concept images: a) and b) first studies that summarize the structure and function of Ecopolitana; c) Ecopolitana structure diagram; d) Ecopolitana logo

Ecopolitana is an idea of city and of territory that is structured firstly on natural systems, and only secondly on infrastructural and settlement ones. It is a concept that utilizes ecological networks as looms and organizes the connection and sustenance relationships on transport infrastructure or on economic and energetic infrastructure: Design (the city) with nature [16]. "Redesign the territory with nature", in this presented case study, has meant "utilizing the environmental systems (woodland, fluvial, agrarian, etc.) as territorial figures and urban form" [17] (Figure 8). Hence the use, in the planning general process, of the "environmental figures" of the Local Ecological Network (Rete Ecologica Locale REL), that are the corridor (environmental), the node (core-area), the filter (buffer-zone) and the spot (stepping stones) as behaviors of the new territorial structure (natural systems, settlement systems, infrastructural systems, etc.), of the new connective structure between countryside and inhabited centers and of the reorganization of the functions (inhabited centers, countryside, productive areas, touristic and attractive areas), and of the relations between natural systems (rivers, lagoon, waterways, riparian woods, etc.) and settlement systems. These figures then, find different project forms inside Ecopolitana, declined as park, from the extra urban scale (theming of the territories) to the urban one (ground design, public spaces, urban greenery), as both implementation instruments (regulations, technical standards and abacus), and territorial configurations and delimitation of areas (theming and zoning). 


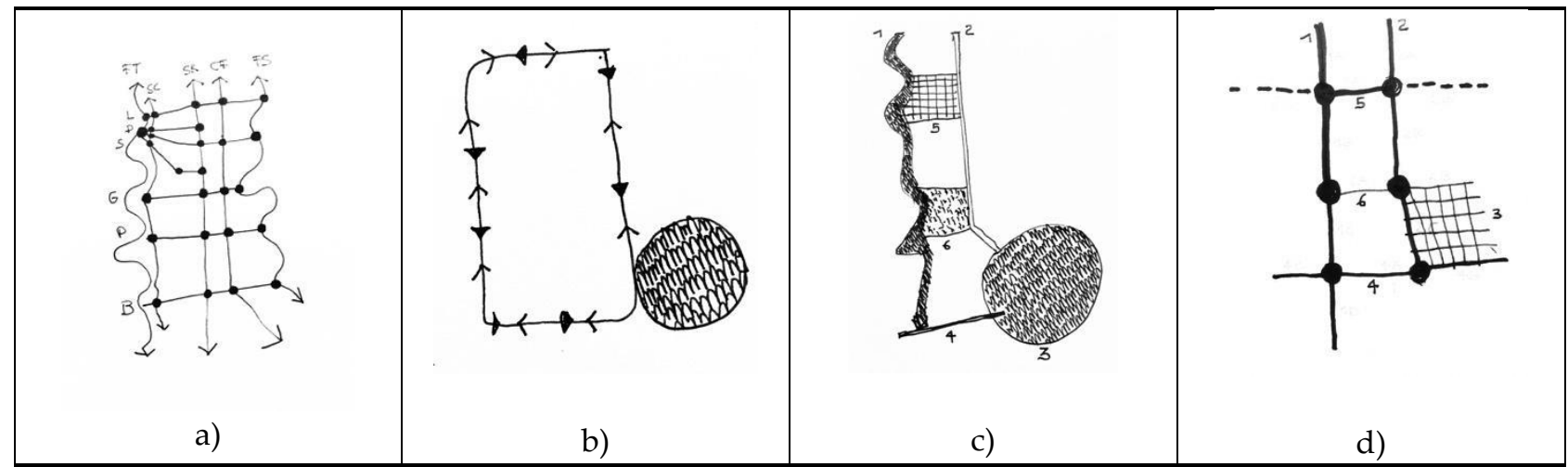

Figure 8. Diagrams of the environmental components as "territorial figures" of the Ecopolitana: a) nodes and corridors that constitute the environmental network and the new urban structure; b) the ring corridor (Fi.La.Re. network) and the Marano Lagoon node (core-area); c) nodes, corridors filters and spots: the components of the environmental/Ecopolitana network; d) Functioning principal of the Ecopolitana on nodes and corridors.

Ecopolitana is a large green infrastructure, a sort of "green subway" (Figure 9), made up of lines (corridors and ecological transects) and stations (core-area, hot-spot and areas of high naturalistic value) that will connect all the range of landscapes (parks). Ecopolitana will, this way, guarantee the capillary connection of the territory, of the landscape patterns [18], the mending of all those rural clusters, that are currently the cause of the ecologic discontinuity and of the high level of environmental fragmentation [19] of the land mosaic di Latisana.

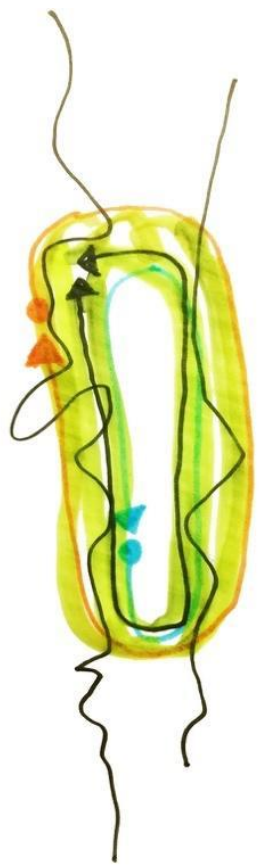

a)

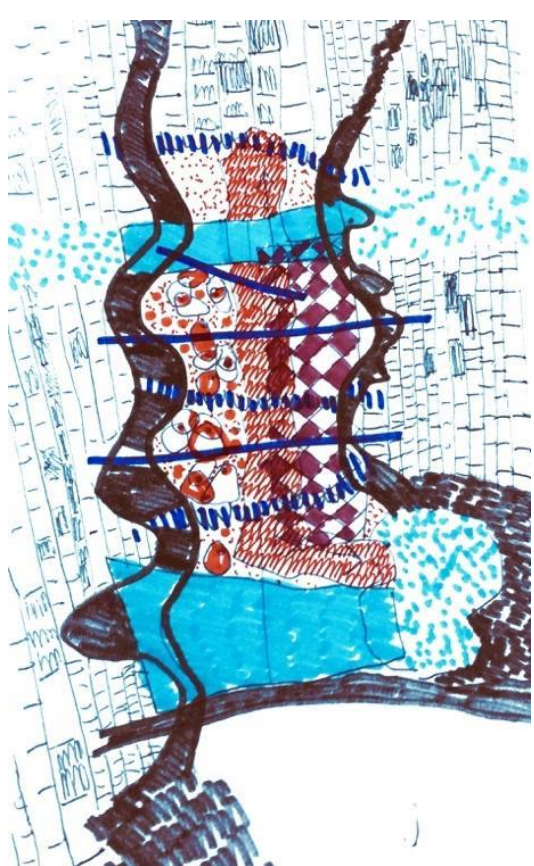

b)

Figure 9. Diagrams of Ecopolitana as green infrastructure and as a settlement-territorial loom: a) "green ring" that connects the Tagliamento river and the Stella river and becomes environmental structure: large ecological corridor of general connection; $b$ ) the "green subway" constructed from the network systems of rivers, ecological transects on rural fabrics, "forest of Latisana", core-area of the Marano Lagoon, settlement systems of inhabited centers and infrastructural network. 
The Ecopolitana then, proposes itself as an ecological concept [20] and at the same time as a structural outline:

On the vast scale (intercommunal) a large green infrastructure, that is a naturalistic skeleton, imposed between two important rivers to the east and west and the lagoon to the south, with a central ridge (the Fossalon canal) and a secondary system of transversal corridors, serves as connections between the two rivers that "bind" the whole landscape unity (Figure 10);

on the local scale (municipal), it is an environmental infrastructure but also a landscape one, conformed as a large green ring (primary structure) made up of linear connectives on hydrographic networks (to the west the Tagliamento river, to the east the Canale Collettore di Bonifica (Reclamation Collector Channel) and to the south the Litoranea Veneta) and from rural connective fabrics (mainly reclamation campaigns), to which it attaches a capillary green network (secondary structure functional to both ecosystem services whose consolidation of the plant structure appears weaker today) spread over the whole territory, that is grafted into urban areas (parks, gardens, tree-lined streets, public areas), peri-urban, agricultural, agro-urban and fluvial areas (Figure 11) effective exactly in the liminal areas between the countryside and the city.

Ecopolitana is in fact a development perspective for the municipal area of Latisana towards the greencity model, with an integrated system of infrastructure-territoryenvironment-landscape [21] that finds its structural reasons for reorganization (strategy of the plan), functional for use (environmental zoning of the plan), relational of conformation and evaluation (instruments for plan implementation) in systems of nature. The general structure of the Ecopolitana is constructed from the Local Ecological Network (REL), the zoning finds its development in landscape systems, through the 3 parks (Figure $11 \mathrm{~d}$ ), the definition of the qualities and characteristics of the public space and of mobility is articulated through the 5 typologies/areas of the urban green and the large ring constituted by the net "Fi.La.RE", the green ring that passes through, characterizes and allows the landscape system to be used.

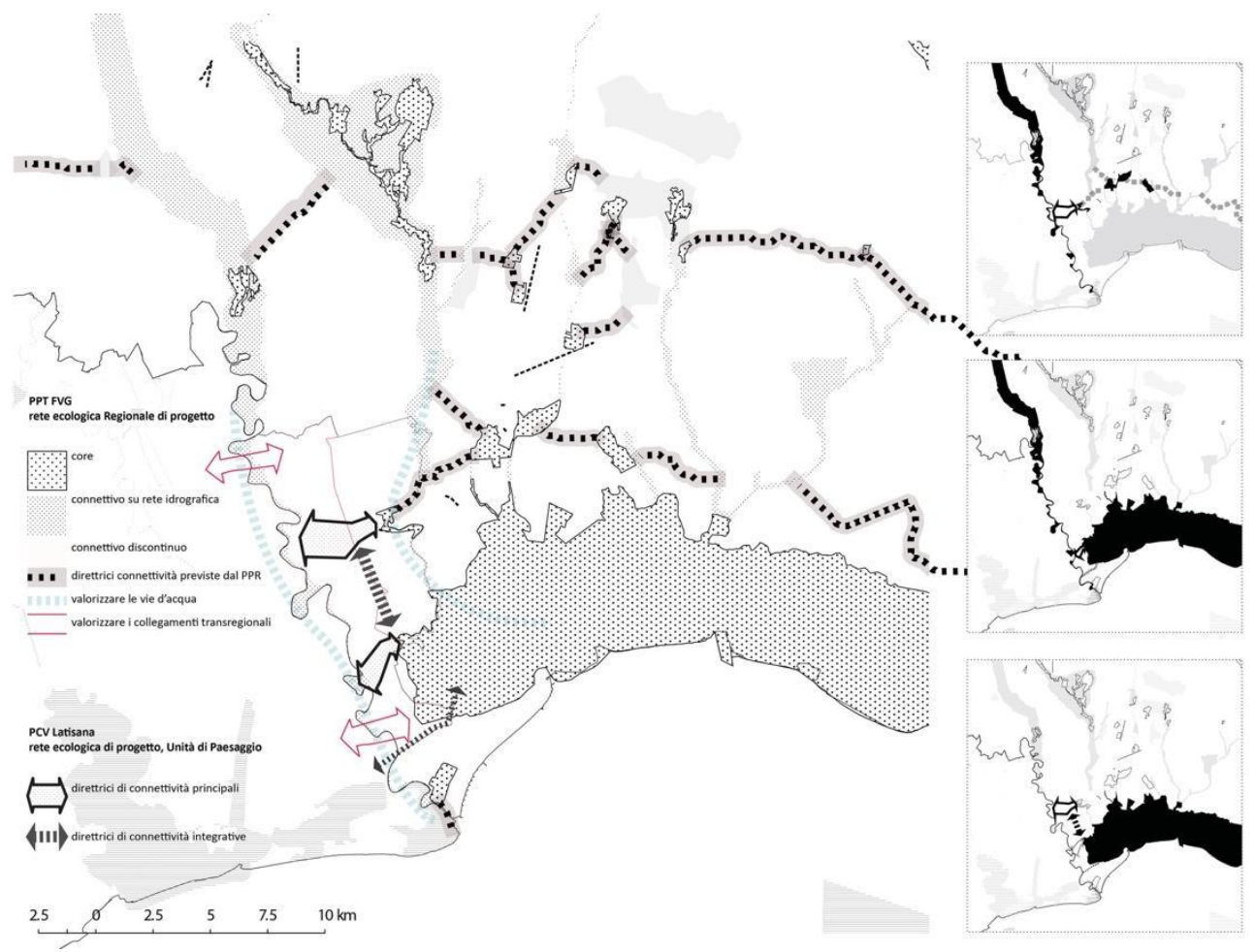

Figure 10. Local Ecological Network foreseen by the Ecopolitana in relation to the RER, Regional Ecological Network, wide area relationships with nature's macrosystems (Marano Lagon, Tagliamento river, "boscovia", regional corridor along the lagoon eaves) and the main and secondary lines (diagrams on the left) 


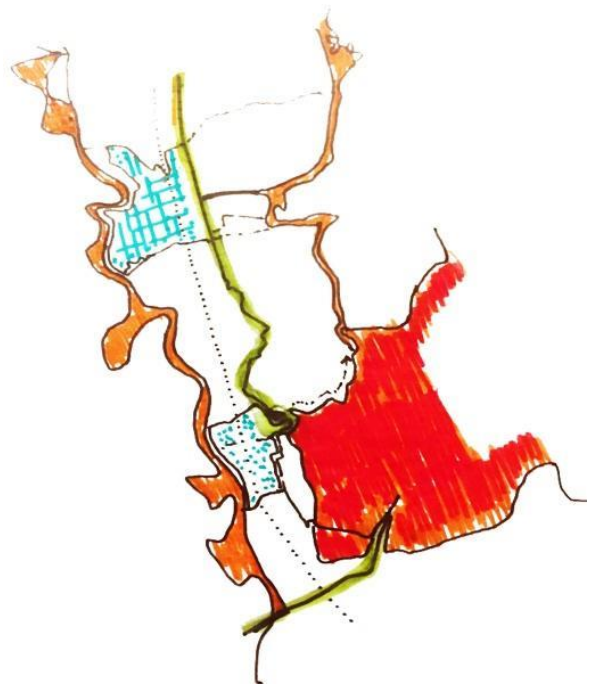

a)

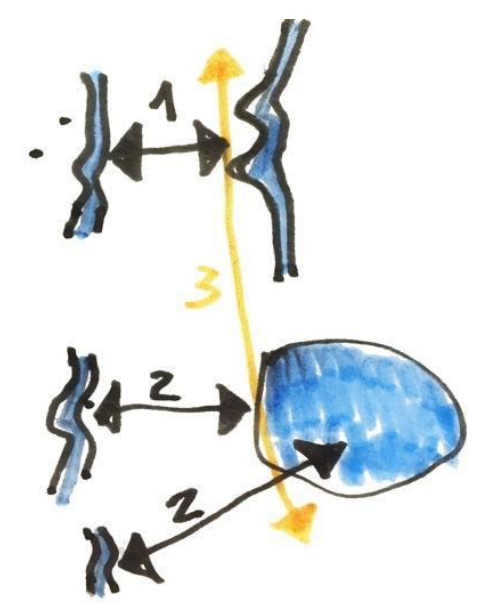

c)

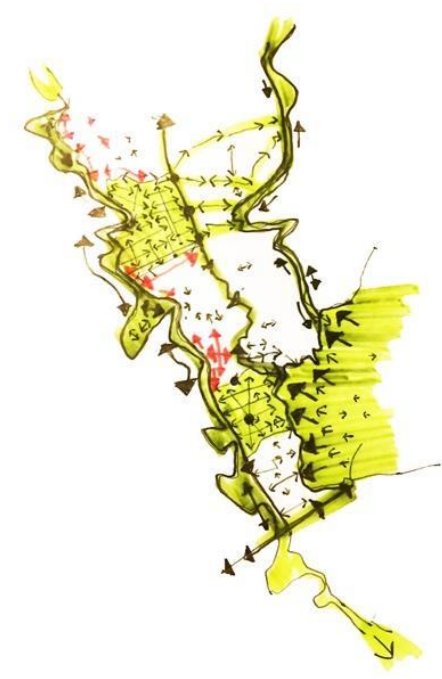

b)

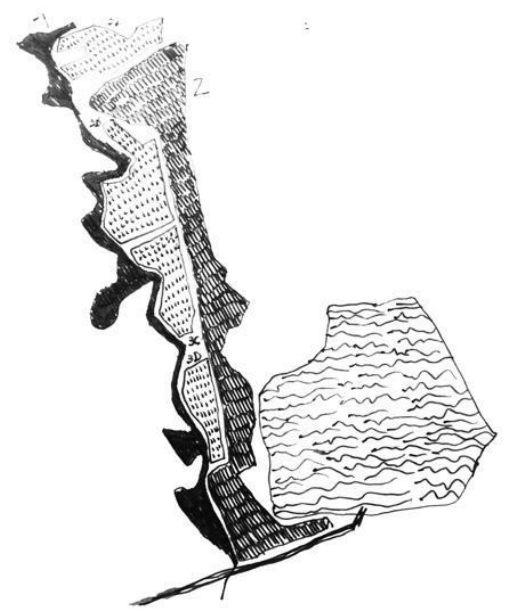

d)

Figure 11. Local Ecological Network foreseen by the Ecopolitana: a) structure of the local ecological network - REL - on the Unity of landscape; b) schematization of the ecosystemic functioning and of the target lines of the Local Ecologic Network - REL; c) primary structure of the REL: 1. Diffused corridor on agricultural fabric between the Tagliamento river and the Fossalon canal, 2.

Diffused corridor on agricultural fabric and contineous corridor on hydrographic network (Litoranea Veneta) between the Tagliamento River and Marano Lagoon (core-area), 3. New continuous corridor on hydrographic network: Fossalon canal); d) landscape systems functioning as "pattern" or "ecological patch" for the ecological network: river landscape, agro-urban landscape, agricultural landscape of reclamation, lagoon landscape. 
Ecopolitana develops five themes emerged during the construction of the cognitive picture: Waters, Agriculture, Urban Green, Landscape Ecology and Tourism. The first three of these five themes are linked to the landscape matrix that characterize the territory of Latisana but are also the "structural components" of the general environmental framework - Local Ecological Network - and the functional organization of the landscape areas - the territorial Parks (Figure 11).

The environmental framework, prefigured for the new overall territorial structure (Figure 12) and built at the extra-urban scale, affects macrosystems of nature, reclamation water networks, canals, river banks and agricultural sectors, in particular: 1. The reclamation campaign; 2. The collector channel Fossalon; 3. The rural territory between Paludo and Gorgo; 4 . The countryside between Pertegada and Maritime Aprilia; 5. The river banks and the riparian areas of the river Tagliamento; 6 . The Litoranea Veneta channel; 7. The agricultural lands between Gorgo and Pertegada; 8. The agricultural territory between Pertegada and Bevazzana; 9. The embankment of the Marano Lagoon. 


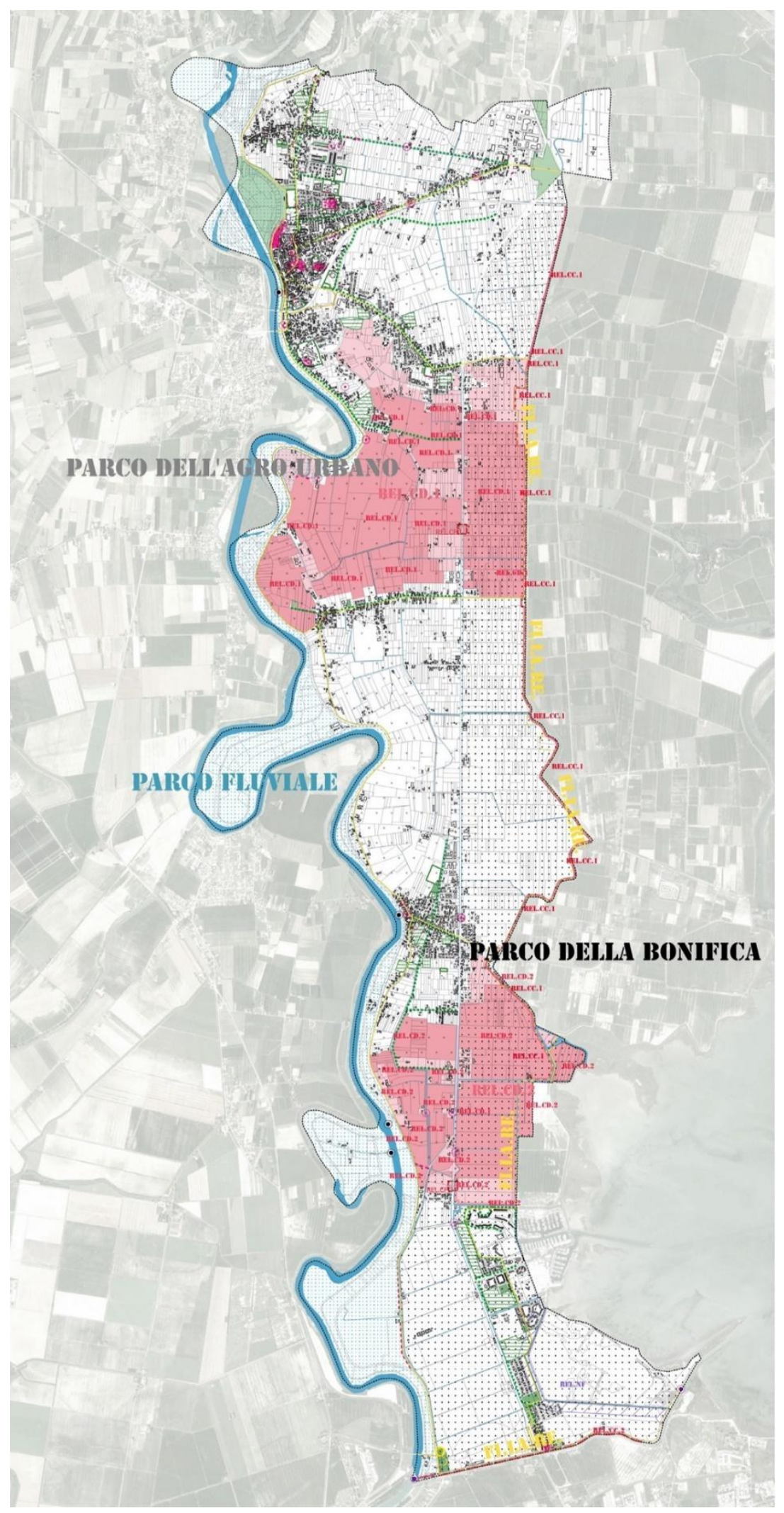

Figure 12. Ecopolitana, new overall structure with the Local Ecological Network (continuous and scattered corridors, nodes, filters, transects), the Territorial Parks, the Urban Ecological Networks and the interventions on the Urban green, the greenway constituted of the perimetral ring (Fi.La.RE. bicycle network). 
Ecopolitana, ecological concept, does not only foreshadow an environmental and landscape transformation but also an overall reorganization of the territory (Figure 12) through dimensions and scales that affect the entire administrative area of the Municipality of Latisana, with wide area (for example the "Boscovia") and intermunicipal (Precenicco, San Michele al Tagliamento, Ronchis, Lignano Sabbiadoro and Marano Lagunare) connections. In line with the theories of Landscape Urbanism [22], the realization of the New Environmental Framework (REL) [23] will also constitute the new urban, territorial and infrastructural anatomy that will accompany the future settlement dynamics through the realization of the 3 territorial parks, (Tagliamento Fluvial Park, Park of the Reclamation and Agro-urban park) and of the $\mathbf{1 0 0}$ interventions on urban green areas.

The new overall territorial structure envisages the enhancement of a widespread nature that exploits the macrosystems present in the area, (the fluvial corridor of the Tagliamento and the Marano Lagoon) placing them in a system, with the still weak but extensive, potential environmental fabric (ecopatch), consisting of the agrarian matrix in its various forms (intensive, extensive) and with the capillary hydrographic network of reclamation. The new environmental frame consists of the integration of the Extra-Urban Ecological Network and the 8 Urban Ecological Frameworks (Figure 13). These components are put into a system (environmental matrix) to build a new territorial structure that develops according to 3 dimensions: morphological, functional and perceptive.

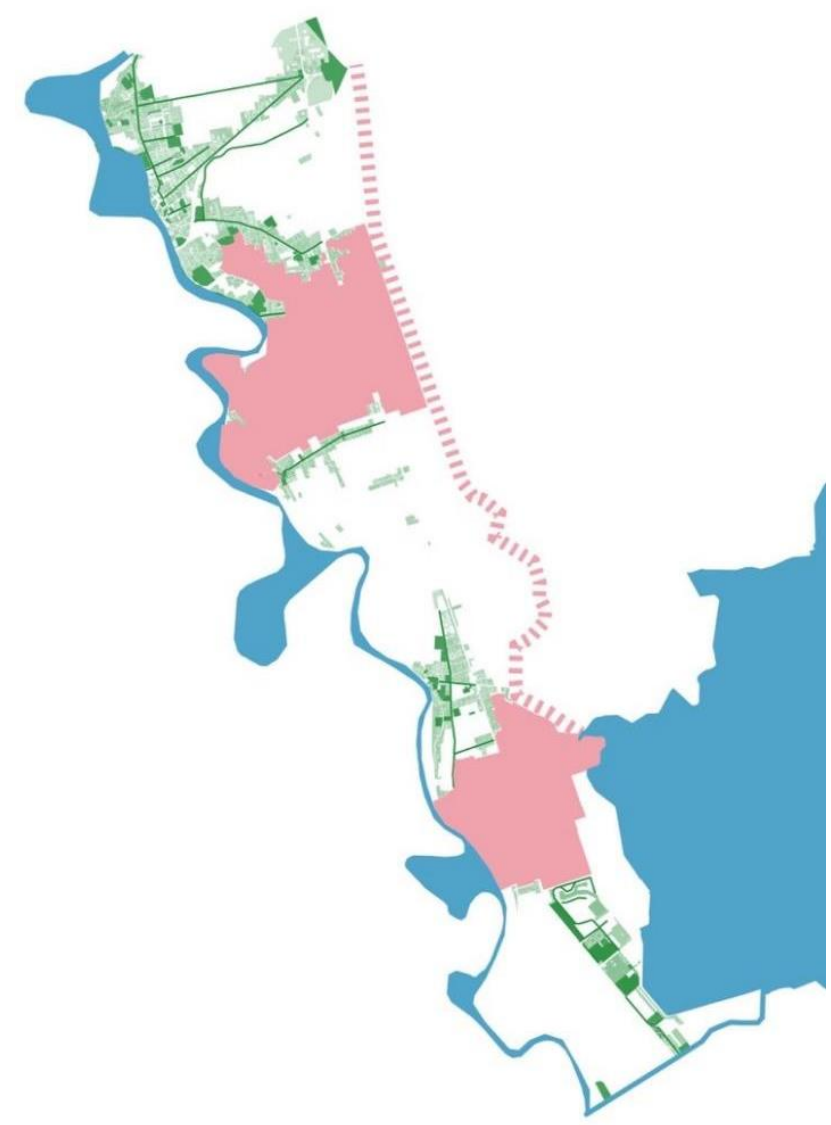

Figure 13. The new environmental and territorial framework is set on the integration of the Extra-urban Ecological Network (in pink) and on the 8 Urban Ecological Networks (in green).

1. Longitudinal arrangement (north-south). Corridors and connectors: the interventions on the enhancement of the hydrographic network and on the recognition and configuration of the 3 territorial parks, (Figure $14 \mathrm{c}$ ) foresees a north-south development and reorganization of the territory according to 3 parallel and continuous bands (homogeneous for territorial functions and landscape features) that develop longitudinally (Figure 14), increasing and encouraging the sliding relations [24] (Figure $14 \mathrm{~b}$ ) and the connection between north and south as the form itself of the system; "terragrams" (Figure 15), continuous and homogeneous systems in which the "spacial patterns" are closely connected with ecological systems, and in particular, with respect to the possibility of movement of all species. This arrangement originates from the natural spatial morphology with "parallel bands" (Figure 14 a) and from the "peninsula", geographic structure of the territory, which is therefore, both the form and structure of the environmental system (REL) and the "corridor landscape sequence" of the three parks. These three "bands" are 3 large corridors and also 3 large connectors, because they constitute a morphological structure for the Ecopolitana, but also a tool for the homogeneous diffusion of naturalness (and therefore an increase in biodiversity): "Biodiversity and mobility of species can be increased by creating corridors or sinks (i.e. small patches) between patches"[25]. 


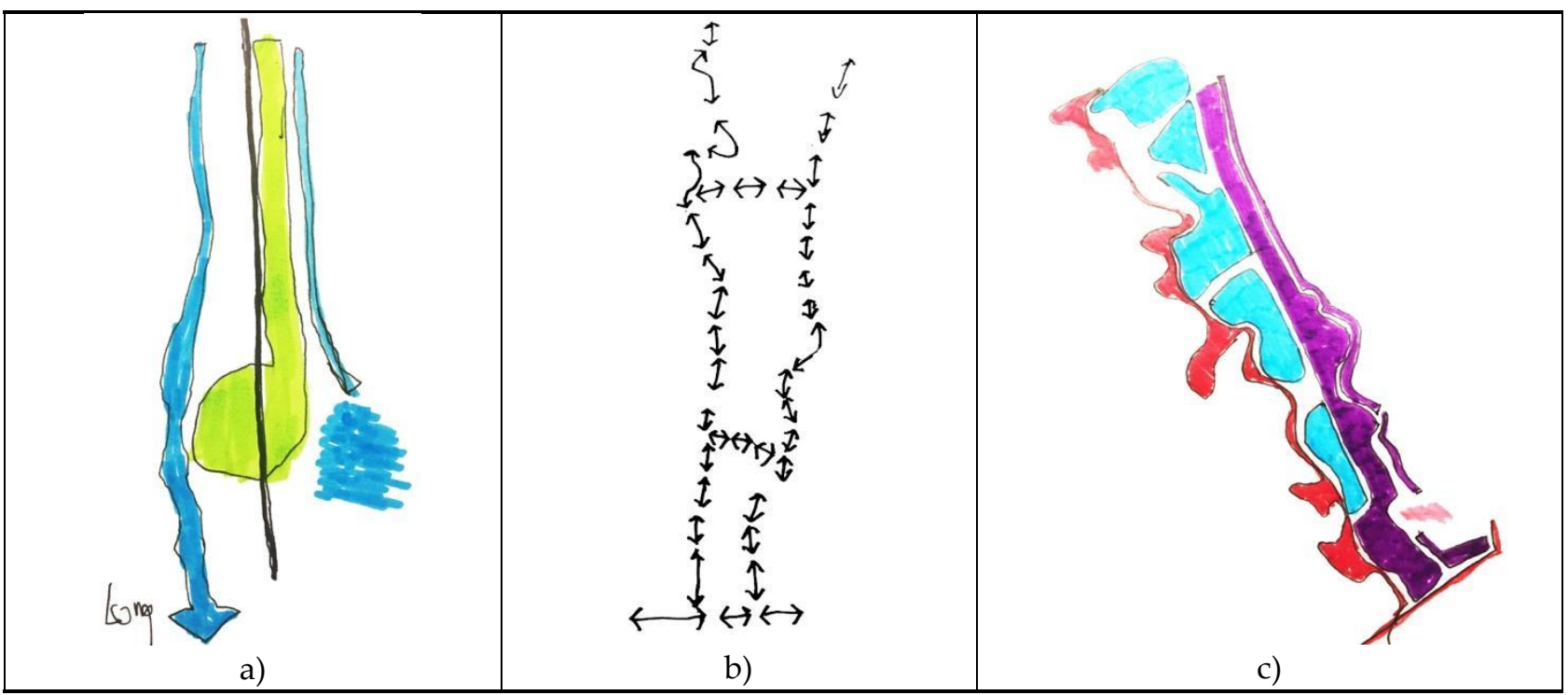

Figure 14. North -South longitudinal structure: a) system of 3 homogeneous and continuous bands; b) sliding relations in the 3 longitudinal bands; c) system of territorial parks (River Park, Agro-urban Park, Bonifica Park) set on the 3 longitudinal bands.

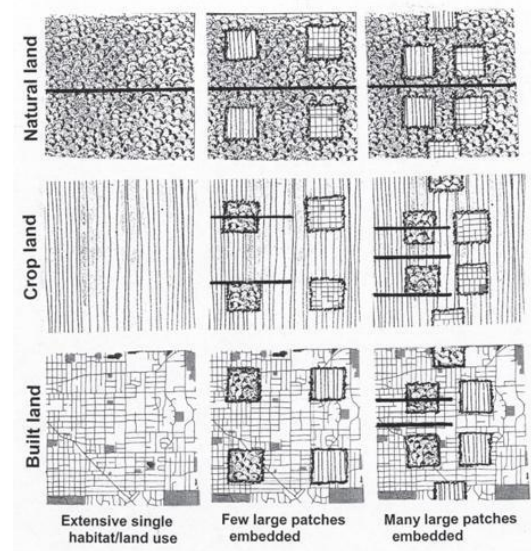

Figure 15. “Terragrams” Forman, 2013

2. Transverse structure (east-west). Stepping stones and patterns: the two ecological corridors spread east-west (between Paludo and Gorgo, between Pertegada-Casette and Aprilia Marittima-Due Pini) - Figure 17 - and the "room" configuration (Figure 16) of the Agro-urban park aim to reverse the current transversal fragmentation of the habitats which over the years has increased due to the compartmentalization caused by the traffic volumes of the SR354 regional road. But starting from the fragmentation of the different landscape fabrics and cells, that function as patterns, it will be possible to build a new ecosystem connection organism, which will also be followed by the infrastructural and later settlement system. In line with the forecasts of the Regional Landscape Plan FVG, the Ecopolitana foresees two large transepts, which function as stepping stones, which have the aim of mending (through the eco-patterns) the environmental and landscape east-west split, (Figure 16) generated by infrastructures and settlement systems grown along the road network. This reorganizational prevision will also constitute new possibilities of east-west relationships (functional but also for the ecosystem) for the whole territory, connecting the great systems of naturalness between the Tagliamento river and the Stella river and in the southernmost part between the Tagliamento river - Marano lagoon (Figure 17). 


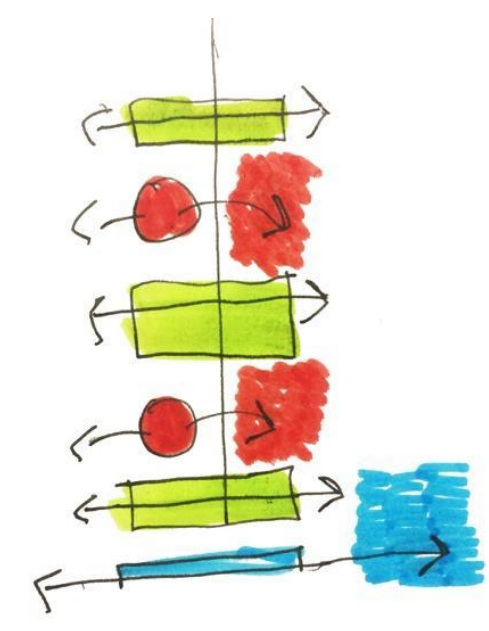

Figure 16. East-West transversal structure of the diffused corridors (stepping stones e eco-patterns)

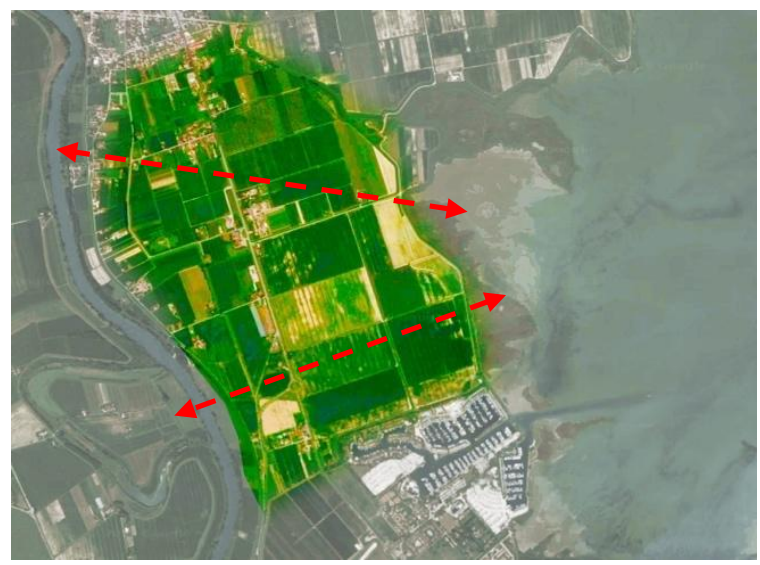

Figure 17. Example of one of the diffused corridors (stepping stone): corridor 2 located south of the territory that connects the Marano lagoon with the Tagliamento river.

3. Overall territorial structure: the integration of the two previous primary "linear" structures with longitudinal development the first, and the transversal the second (Figure 18 a), will lead to the formation of a more complex structure, made of a "net" (Figures 18 $\mathrm{b}$ and $\mathrm{c}$ ): the green network of the Ecopolitana. This new overall structure, hierarchized on 3 levels, will give rise to a new functioning of the nature systems, more capillary but also more structured, from which a new landscape quality can develop, which, as previously mentioned, will be based on the recovery of the main matrices that characterize this Landscape Unit (water, agriculture, urban green):

level 1: environmental frame: structure (Figure 19 a)

level 2: system of the 3 territorial parks: areas (Figure $19 \mathrm{~b}$ )

level 3: urban green and "figures": settlement system as a landscape system (Figure 19 c) 


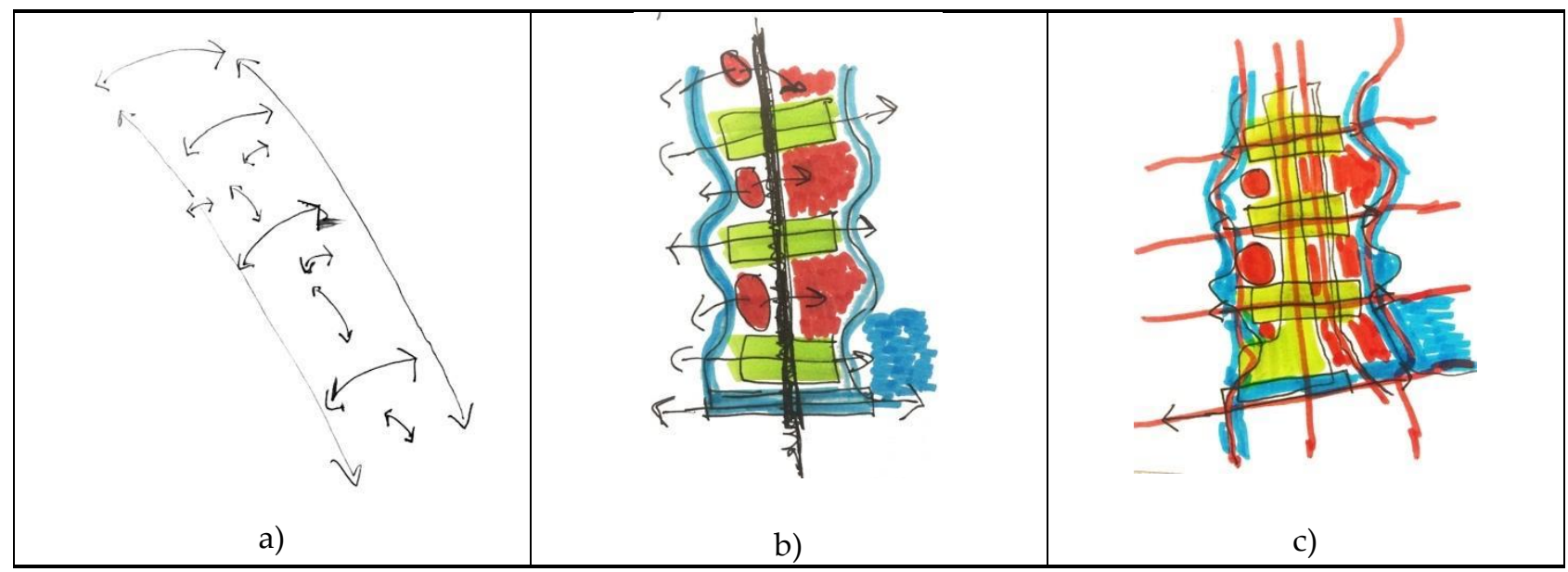

Figure 18. Overall "network" territorial structure: a) new connection lines; b) and c) Ecopolitana green network.

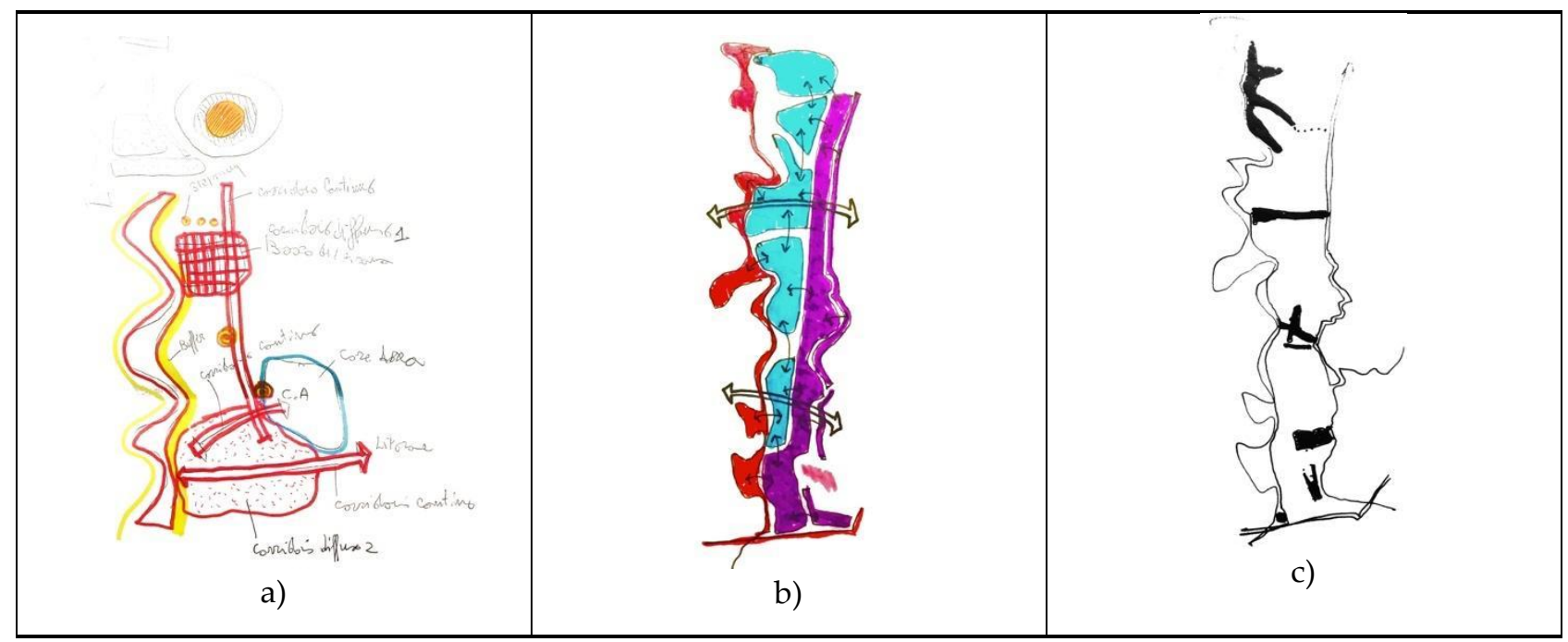

Figure 19. Overall "network" territorial structure: a) new connection lines; b) and c) Ecopolitana green network.

The Ecopolitana as a "figure" of the new overall territorial structure, is implemented through 4 systems, which also organize all the detailed projects envisaged by the plan. The four systems are:

1. the new local ecological network (REL)

2. the Fi.La.RE ring, a slow mobility network and greenway system

3. the urban green and the 8 ecological networks

4. the 3 territorial parks

\section{La REL, Rete Ecologica Locale}

Ecopotamia introduces a method not exclusively for the protection and enhancement of existing resources, but for the definition of an ecological and landscape network in the planning sense, by building new corridors where they are lacking today [26] (Figure 20). This will constitute a landscape-environmental frame aimed at characterizing the entire structure of the open space, contributing as much as possible to the formation of the RER [27], and also directing local urban planning towards a new vision of settlements, with the ecological dimension at the center [28].

The structure of the local ecological network introduces elements of protection and enhancement and totally new elements that will have to deal with a scarcely connective context; each component (core area, corridors, stepping stone, etc.) will therefore be 
characterized by specific modes of operation in relation to the estimated ecosystem services.

The REL construction strategy first of all foresees the conformation to the RER confirming:

- the Tagliamento as connecting corridor on the hydrographic network;

- the Lagoon as Core Area;

- the corridor suggested on the regional scale (bends of the Stella river - bends of the Tagliamento river);

and adds a further corridor to exploit the mutual proximity between the Tagliamento River and the Lagoon, and therefore connect an effective core-area (the lagoon) with an area that is not currently defined as such, but has the environmental characteristics to become one.

The two diffused corridors planned in the East-West direction represent the main lines of connectivity.

Also foreseen are:

- an integrative connectivity route, in a south-north direction, which connects the lagoon with the main corridor to the north, to be built along the drainage canal (Fossalon canal - Figure 21) on the border between Latisana and Precenicco;

- a secondary integrative route is also to be built along the Litoranea Veneta (corridor on a hydrographic basis).

This way, the REL composes a frame structure (Figure 20), with circular operation in every direction (Figure 20) which maximizes - given the scarce existing connectivity - the potential local ecological connectivity in relation to that of the regional scale [29].
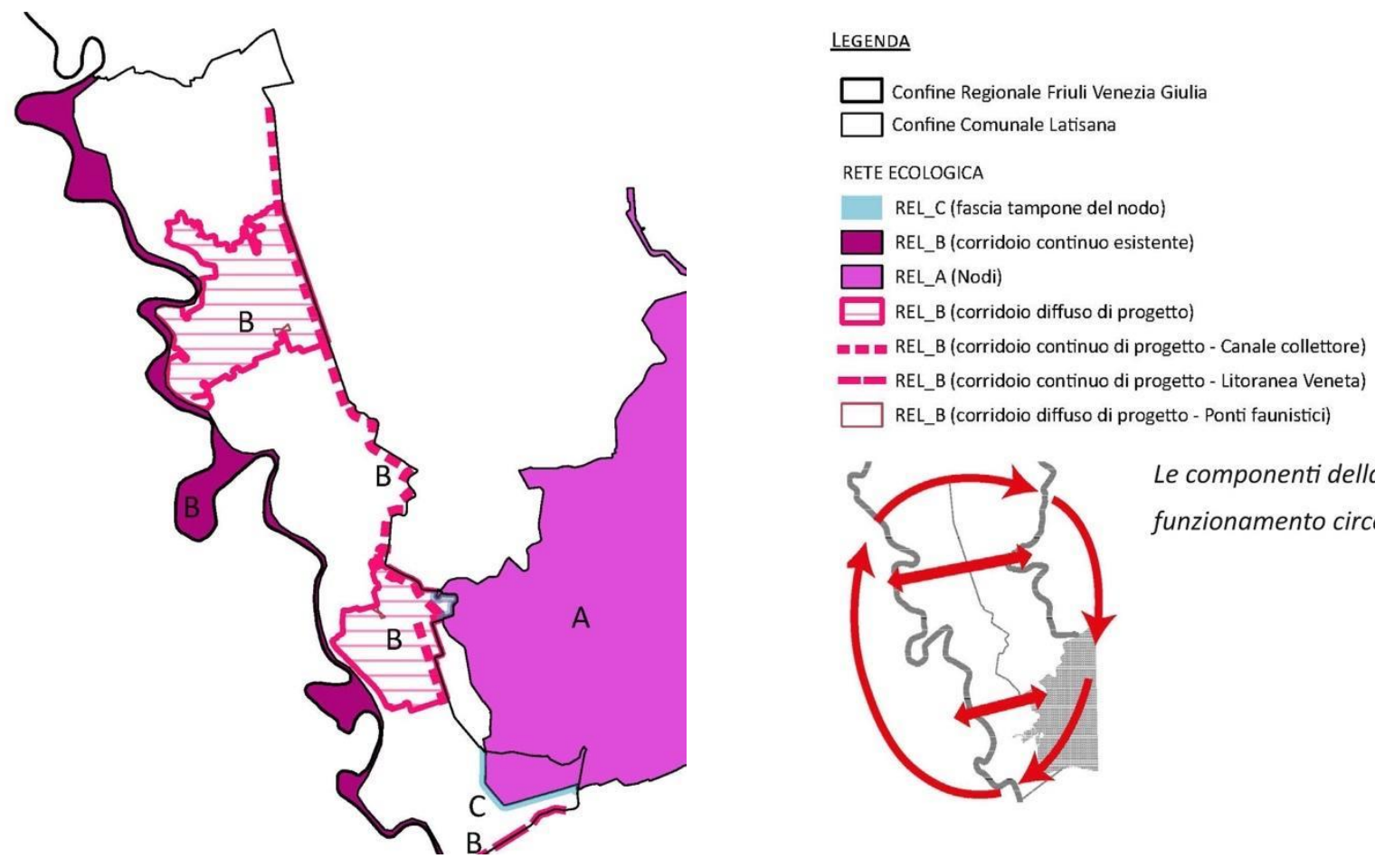

Le componenti della REL e lo schema di funzionamento circolare

Figure 20. Diagram of the new REL, Local Ecological Network: components and operations. 

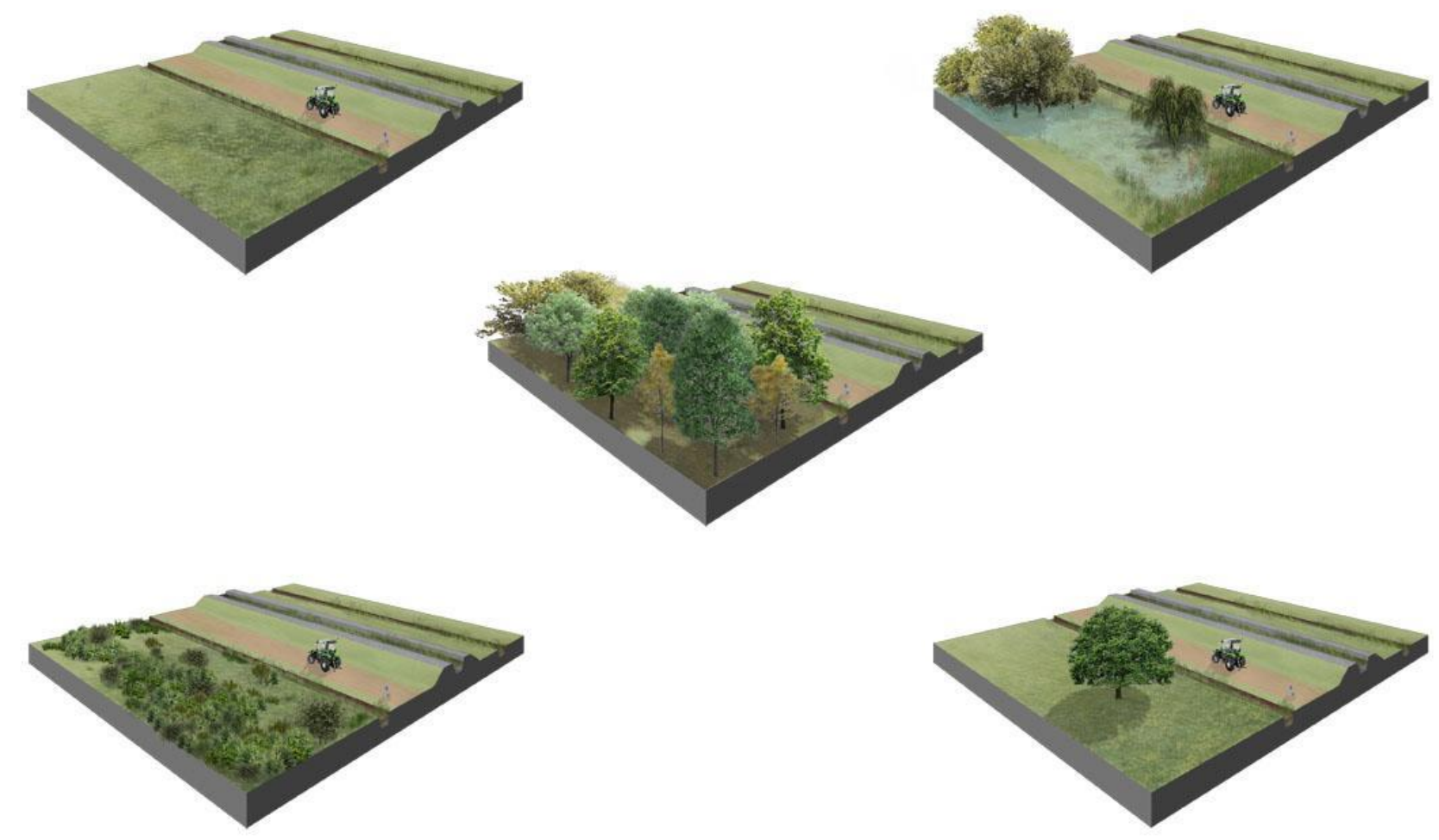

Figure 21. REL, Local Ecological Network: Photo simulations of the minimum environmental units for the formation of the continuous corridor on the hydrographic network along the Fossalon canal.

\section{The 3 territorial parks}

All the necessary interventions for the territorial and landscape reorganization (extra-urban) described in the previous paragraphs are organized by means of the 3 territorial parks (Figure 22). Within the municipal area, three homogeneous areas have been identified in terms of formation, landscape structure, settlement and functional characteristics: the Bonifica Park, the Agro-Urban Park and the River Park.

The "park" constitutes the territorial unit of reference and the instrument of territorial governance in order to achieve the objectives set by the Ecopolitana:

- enhance and develop the landscape and environmental dimension of the territory;

- contribute to the construction of the Local Ecological Network (REL);

- implement interventions and activate use practices related to the environment and landscape as attractors;

- characterize the territorial areas with themes linked to local productions (farm to table) or landscape excellence (for example fluvial areas or those of land reclamation);

- to encourage the economic, touristic and socio-cultural development of the area, the territorial parks will be created through specific projects that will enhance its value by transforming the various peculiarities related to water (River Park and Bonifica Park - Figure 23) or to agriculture (Agro-urban Park or Bonifica Park), into thematic categorizations and characterizations, working on territorial marketing to develop new economies or on activities, productions and hospitality already present in the area, to enhance the existing. This way the parks will also become tools of promotion and usability of the territory recognized as a system. 


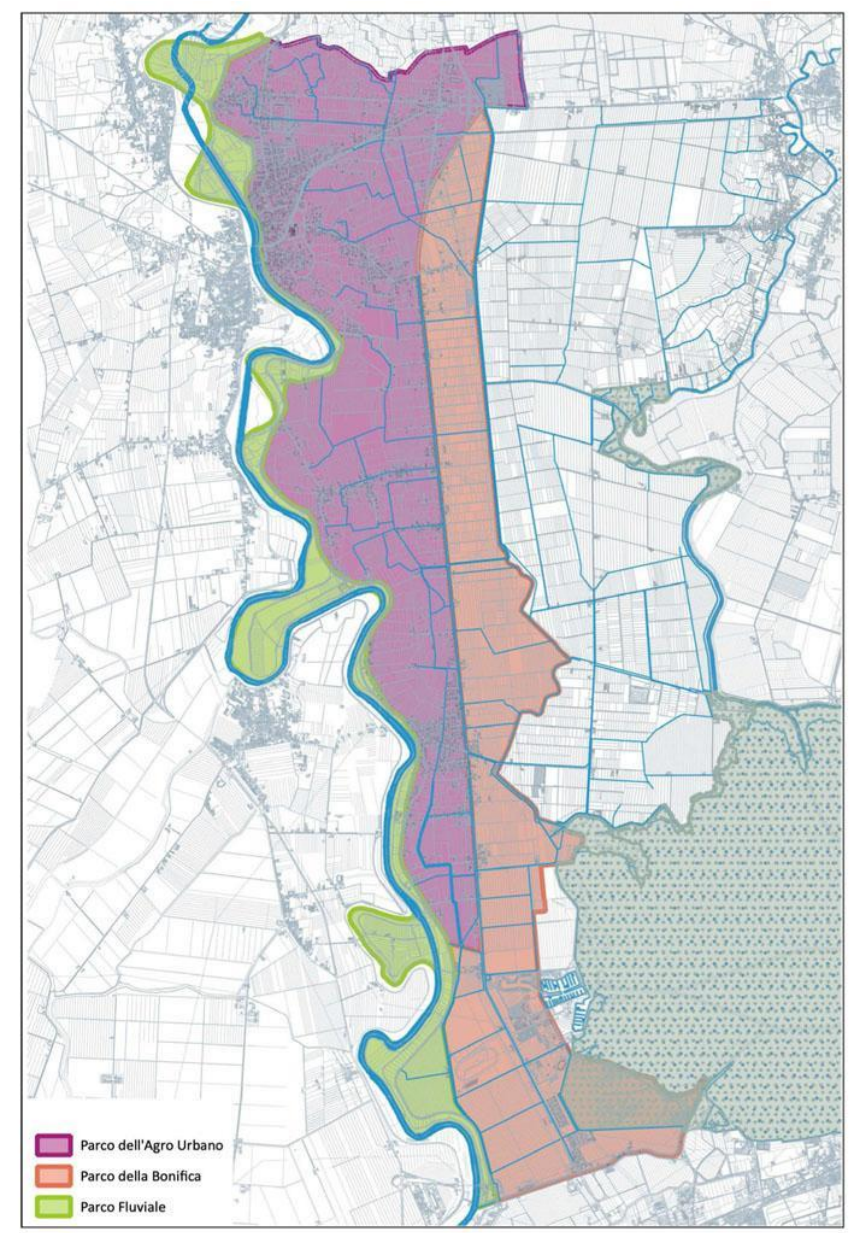

Figure 22. Sistema dei 3 parchi territoriali: (da sinistra) Parco Fluviale, Parco dell'Agrourbano, Parco della Bonifica
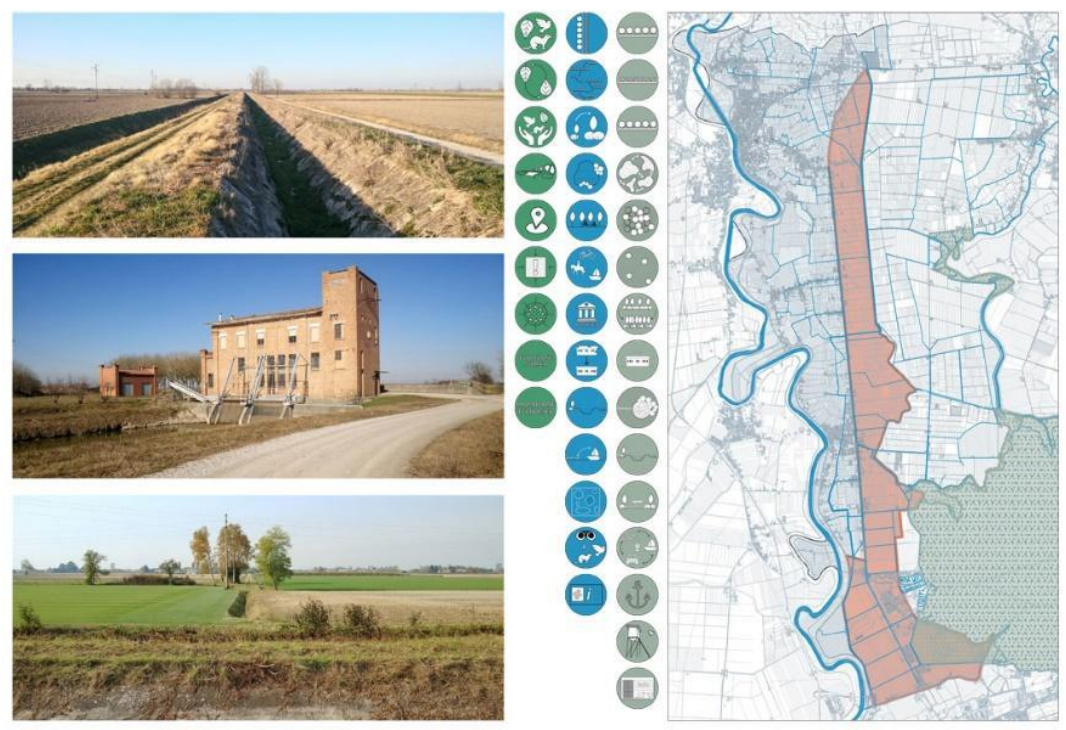

Figure 23. Immagini del parco della Bonifica con l'edificio dell'Idrovora "Lame" che diventerà centro visite e museo del parco

The Fi.La.RE, slow mobility network and greenway system 
Introduced primarily as a solution to the problems related to urban traffic congestion, over time, slow mobility has taken on further, no less important values, referring to the use of the landscape, the management of leisure time, the maintenance of physical wellbeing, the cultural education.

The large territorial ring of slow mobility envisaged by the Ecopolitana and called "Fi.La.Re." contains and develops the layout of the cycle network within the municipal area (along the entire perimeter), as well as the interventions envisaged by the Ecopolitana for the pursuit of the objectives related to the new vision of slow mobility (Figure 24 a):

- integrate the network of the planned cycle paths with landscape enhancement strategies;

- enhance the use and attractiveness of the overall cycle network in relation to the landscapes crossed (Figure 25);

- connect the network in an integrated way with the Local and Regional Ecological Networks, and with the circuit called "Boscovia" already existing in neighboring municipalities.

The large ring "Fi.La.Re." develops the following interventions:

- incorporates the ReCIR (Regional Cycle Network), completes and closes the overall circuit, integrating it with two new important sections at the local level: the cycle path of the Collector Channel (Canale Collettore) and that of the Litoranea Veneta;

- integrates the network of municipal cycle paths into the system of the 3 territorial parks, for capillary use from a tourist point of view, foreseeing the introduction of rest areas, information systems, direct connections with the waterways (Figure $24 \mathrm{a})$;

- builds sections of cycle paths in the form of greenways, to contribute to a more comfortable use, to the landscape valorization of the territory and to the recognizability of the routes;

activates a territorial marketing process (Figure $24 \mathrm{~b}$ ) for the more direct and tangible diffusion of the Ecopolitana project, through the definition of a logo for the name Fi.La.Re., which must be followed by all disclosure and communication actions, also in a participatory way with citizens, stakeholders and the environmental constitution of a "Park Authority" for the creation and management of the territorial Parks.

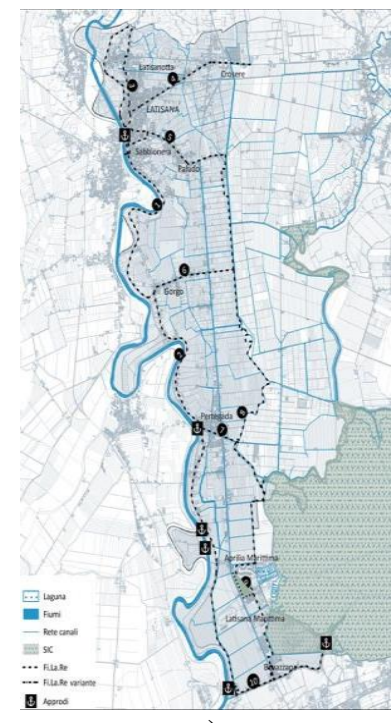

a)
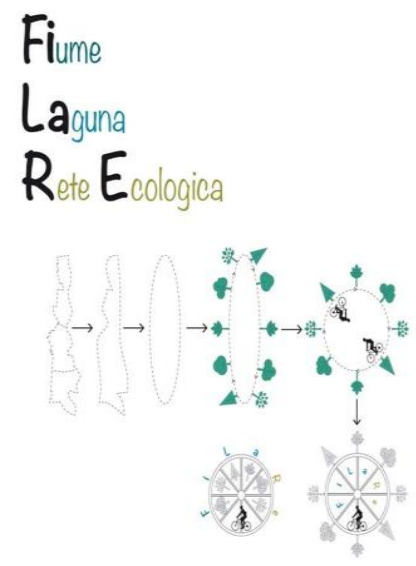

b)

Figure 24. Slow mobility ring "Fi.La.Re.": a) diagram of the Fi.La.Re. path; b) Logo, logotype and first indications for the coordinated image of the "Fi.La.Re." for territorial marketing actions. 

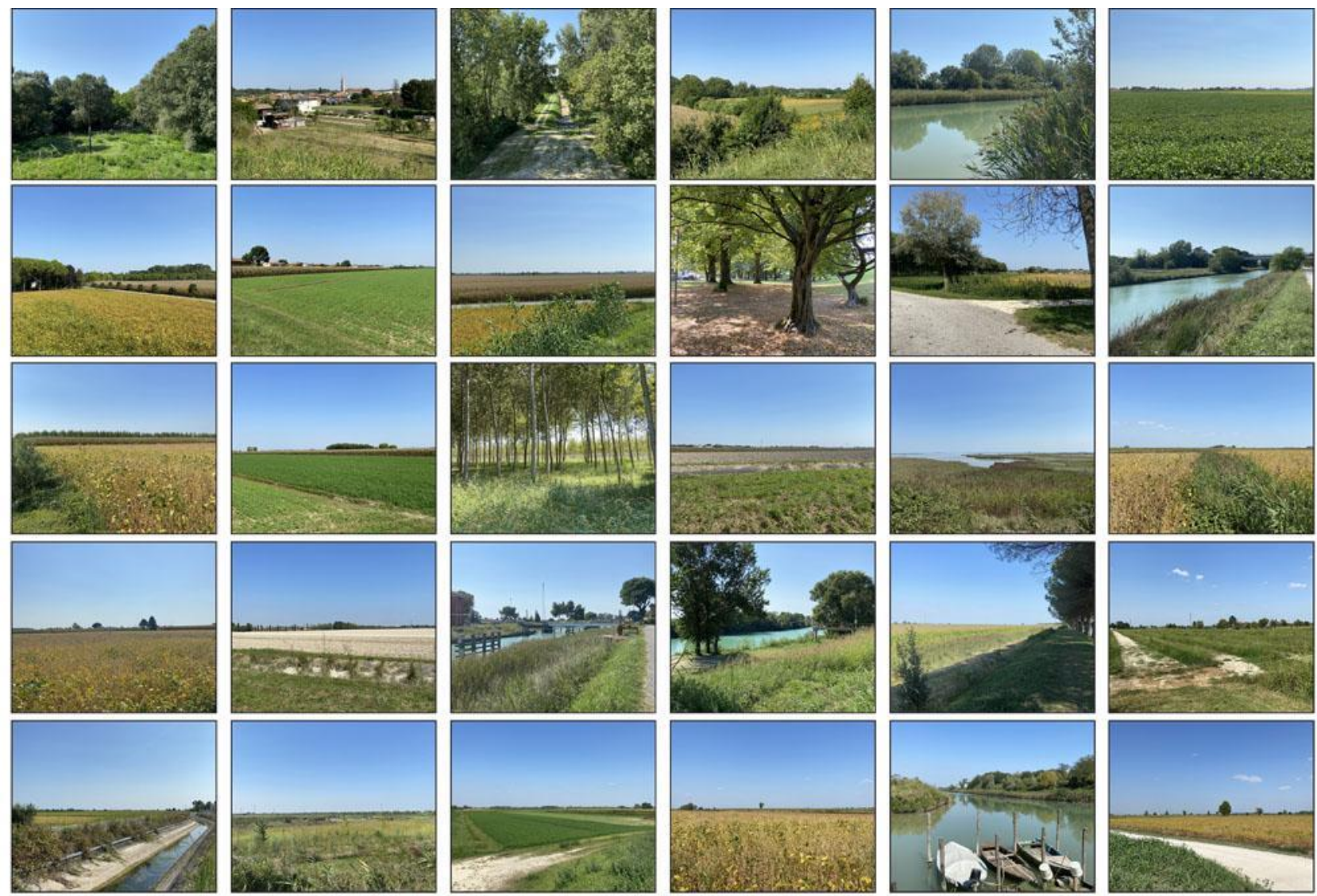

Figure 25. Abacus of landscapes crossed by the ring of slow mobility "Fi.La.Re." foreseen by Ecopolitana.

\section{Urban green and the 8 environmental networks}

The urban green system identified by the Ecopolitana involves the 8 inhabited centers of the Municipality of Latisana (Figure 26) and organizes the entire vegetation system (landscape and environmental) in "structural green", the one aimed at creating the ecological network, and in "scenic green", (Figure 28), the one that contributes to the construction, definition and characterization of urban scenes and public space.

Ecopolitana, in line with morphotypes identified in the analysis phases, plans the Urban Ecological Networks of each inhabited center in the municipal area that are integrated with the Local Ecological Network. Specifically, the Ecolopitana assumes the structure of the private urban green as a basic structure (latent landscape) completed by that of the project of the public urban green. The result is an autonomous structure, for ecosystem services, for ecological and environmental continuity and for landscape layout and function: the Urban Ecological Network (REU). The system of the 8 Urban Ecological Networks (one for each inhabited center) constitutes an important step in the completion and stabilization of the Extra-Urban Ecological Network. Together they form the Local Ecological Network of the Municipality of Latisana, which in turn is a piece of the Regional Ecological Network (RER), and in particular of the great east-west ecological corridor along the low Friuli, Isontina plains and lagoon eaves.

The general strategy of the Ecopolitana for urban greenery foresees the creation of east-west (from the Tagliamento towards the interior of the territory) continuity systems of ecological landscape (urban) through linear ecological corridors and widespread urban corridors, continuous and in some cases discontinuous, (according to the "stepping stones" model) essentially constituted by the sequence of environmental tiles formed by parks and gardens, green areas pertaining to buildings, road rows and flower beds (Figure 26). For the formation of these frames, the private gardens of residences and buildings were also considered (Figure 26), which, even with minimal contribution, still provide an 
ecosystem service and in many cases, play an important role in ecological training and structure for the landscape layout of each individual urban center (Figure 28).

Ecopolitana organizes urban green in 5 sections, types/areas of intervention, and each section is located in the 8 inhabited centers, within which the 96 interventions are located (Figure 26).

The 5 types/areas with which the interventions are organized are:

Road green: the 19 areas are mainly made up of rows of trees along the street networks, whose main purpose (ecological and landscape) is to stabilize the internal structure (landscape and scenic green) and to create ecological continuity, as well as connection (corridor) with the Extra-urban Ecological Network. This is centered on the rows along the road networks.

\section{Gardens, parks and public green areas}

This type involves 23 sites including parks and gardens, as well as standard green areas, often the result of new subdivisions. These are equipped green areas (urban furniture, paths, games and services) with an explicit function as dedicated space for public and community use.

\section{Green spaces belonging to public buildings ( 31 sites)}

This type involves all green areas belonging to public buildings which often have a limited public function because they are not always explicitly dedicated to open collective use (for example the gardens of schools or kindergartens, green areas belonging to churches or rectory). It is therefore a public green that is not always equipped but given the location, the numerosity (31 sites) and the arboreal heritage present, it has an important collaborative and consolidation function for urban corridors (structural green) as well as having a high landscape potential (scenic green) within residential fabrics.

\section{Areas of expansion and completion subject to unitary planning (17 zone)}

Ecopolitana, within the Urban Green scope, addresses the solutions for the "standard or assigned green" of all areas subject to implementation planning (Zone "C" e Zone $\left.\mathrm{AM}^{\prime \prime}\right)$. The objective of Ecopolitana is to insert the 17 interventions of the related "strategic" sectors in an overall framework for the formation of the Urban Ecological Networks to establish connection nodes between the Extra-urban Ecological Network and the Urban Ecological Network.

\section{"Strategic" unitary projects}

A determining role, on different scales and areas (local and territorial, landscape, environmental, urban planning and public space) is assumed by the "Strategic unitary projects" foreseen by the Ecopolitana, as they are hinges and environmental nodes of connection with the Local Ecological Network, but also with the most important landscape and naturalistic systems of the territory such as the Tagliamento river or the Litoranea Veneta. All 6 cases foreseen by the Plan involve large areas that, in addition to the landscape and environmental potential, play an important urban role with respect to the settlement fabric, the urban functionality, the local mobility, the provision of public space and overall accessibility to inhabited centers. 


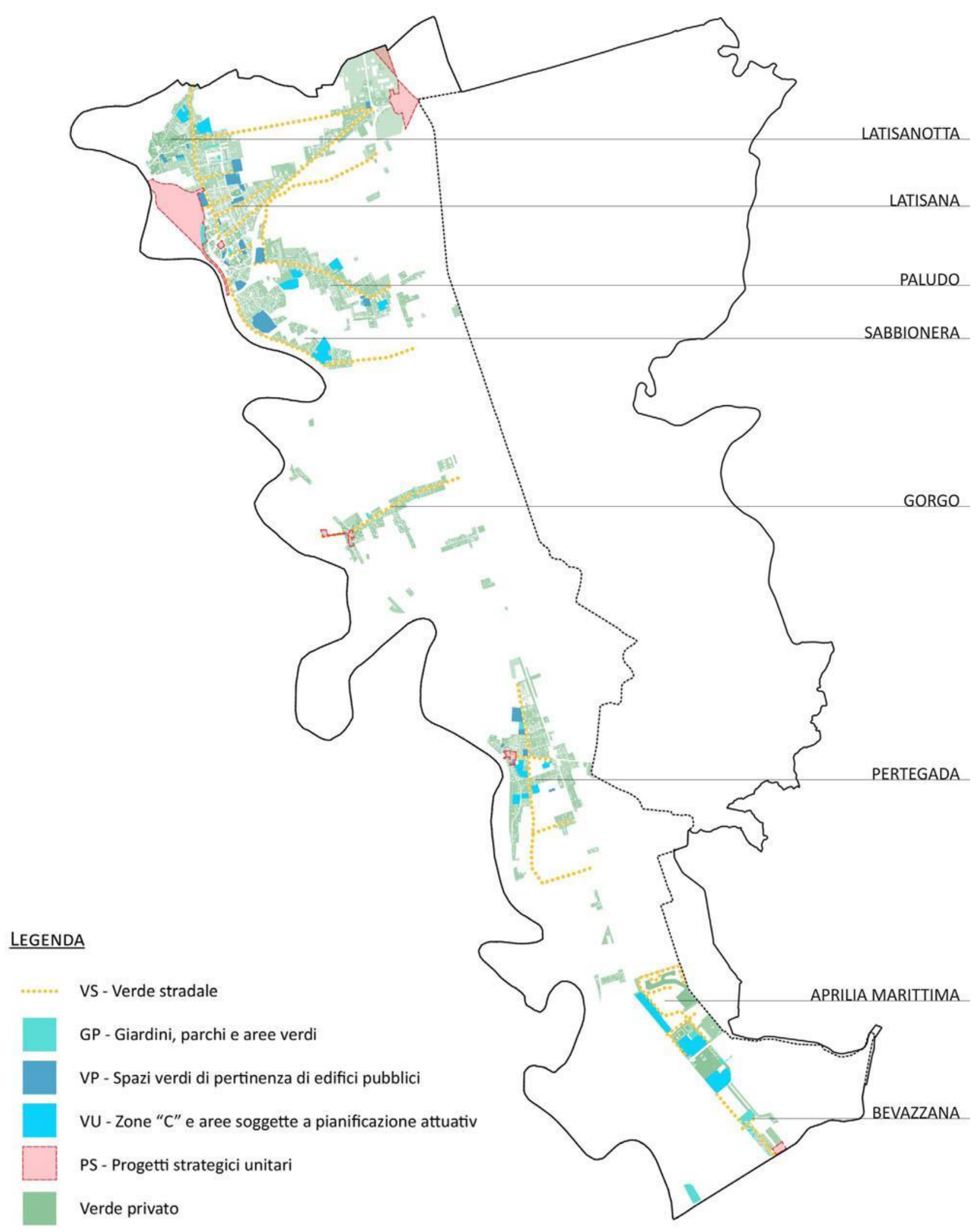

Figure 26. Urban green systems of the 8 inhabited centers in relation to the 5 types/areas of intervention for the formation of Urban Ecological Networks. 


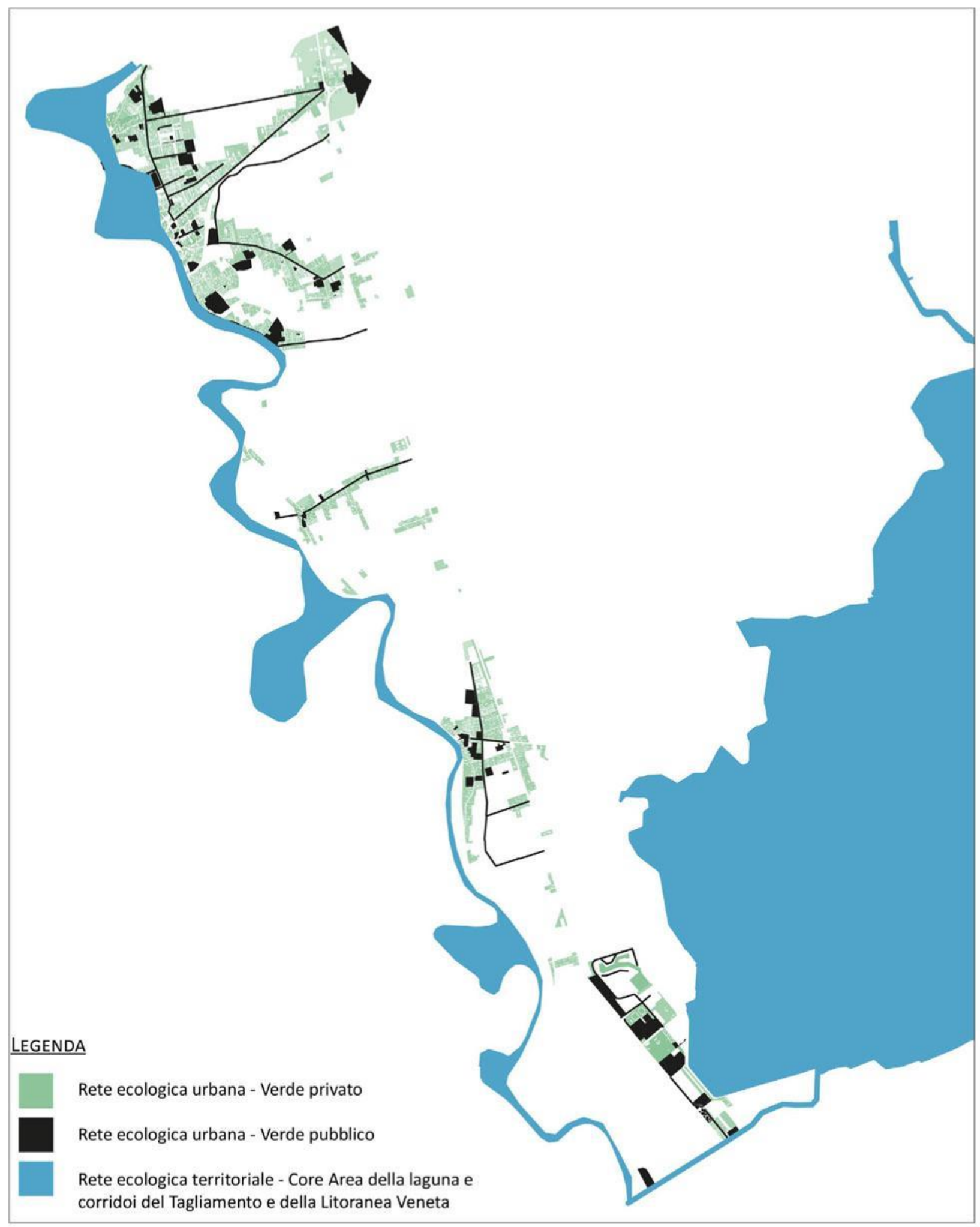

Figure 27. The Urban Ecological Networks in the 8 inhabited centers. 

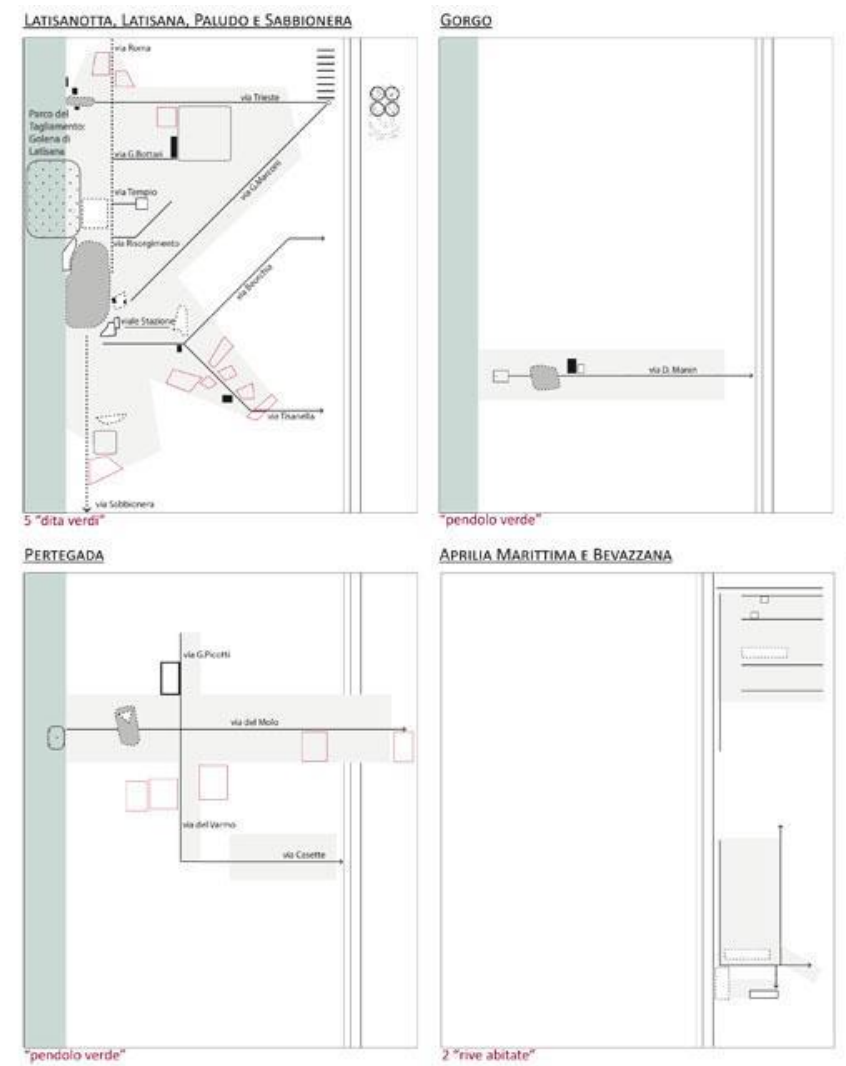

LEGENDA (IMMMAGINIA SINISTRA)
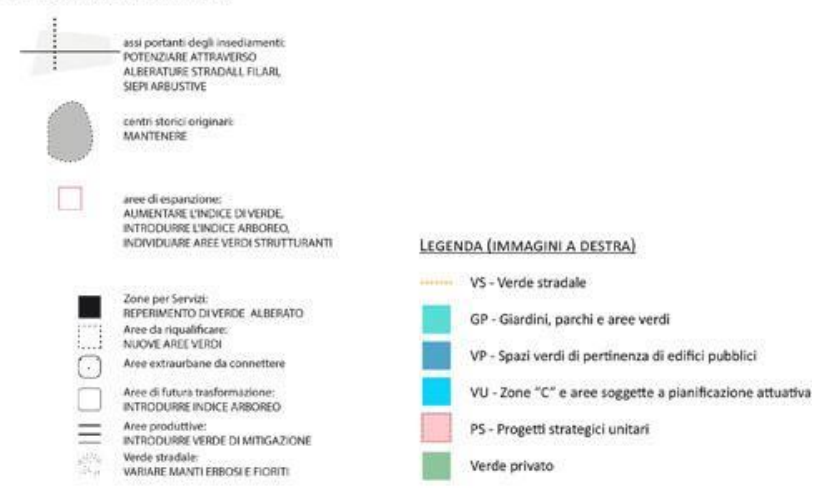

Figure 28. Outline in "urban figures" (structure and functioning) of the Urban Ecological Networks foreseen by the Ecopolitana for the 8 inhabited centers. 
In line with the purposes defined by Ecopolitana, the following are the results of the comparison made between the current state of the Latisana countryside and the sustainable farming ecosystem already in place in the Plasencis countryside.
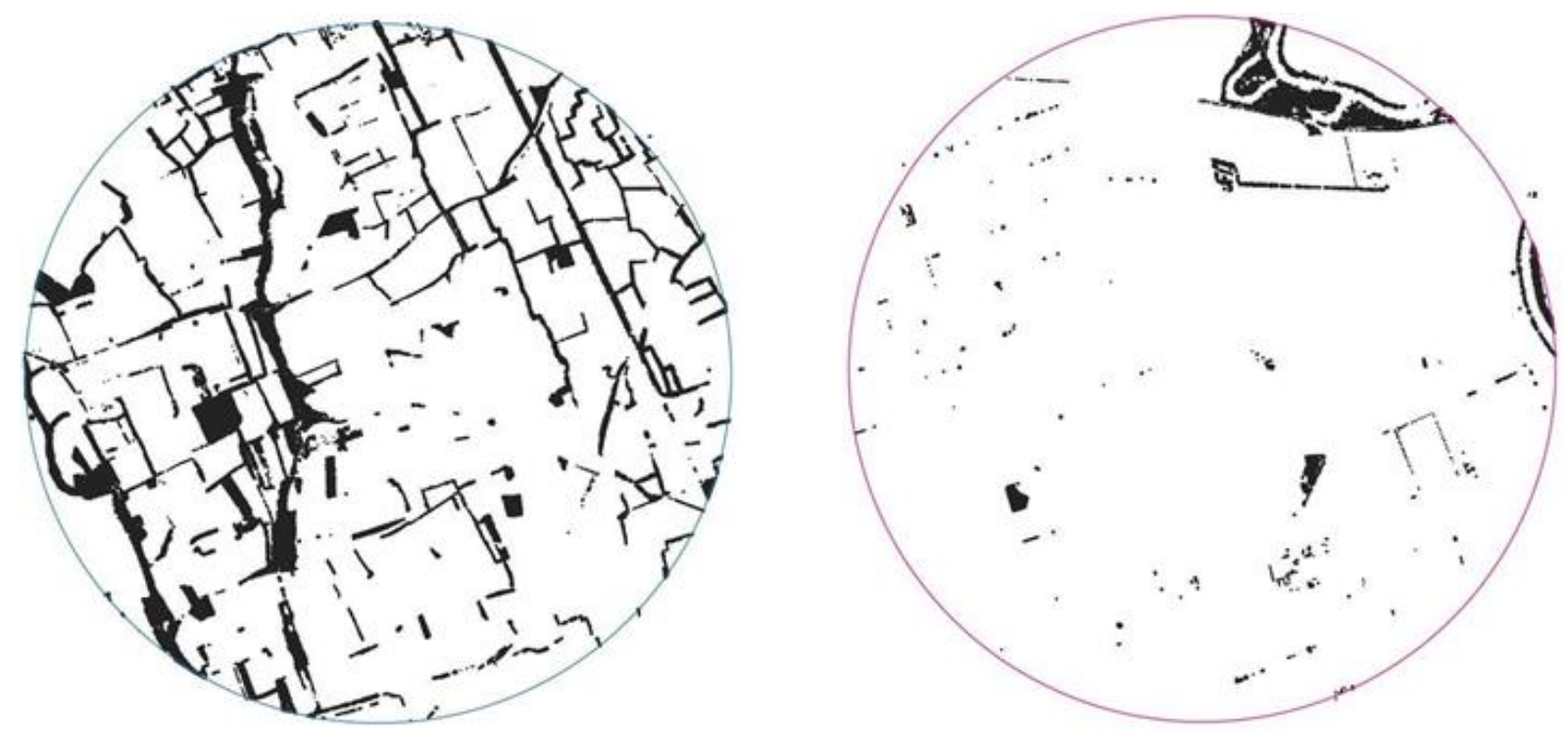

Figure 29. Vectoral representation of the linear and punctual elements of the "Plasencis" sample (left) and the "Latisana" sample (right), obtained by processing the LiDAR data.

As can be seen in Figure 29, the agro-archaeological infrastructures within the sample area of the Plasencis countryside are visibly more consistent and numerous compared to the Latisana countryside. They cover a surface area of 65.8 ha out of 676 ha of farming land, which corresponds to $9.7 \%$ of the total surface area examined. The fields declared by IRDAT-FVG to be used for conservative agriculture, illustrated in Figure 30 for the Pasencis area only, constituted $14.9 \%$ of the sample area, covering a total surface area of 100 ha. As a result, $24.6 \%$ of this area is formed by natural and semi-natural elements and by "sustainable" soil.

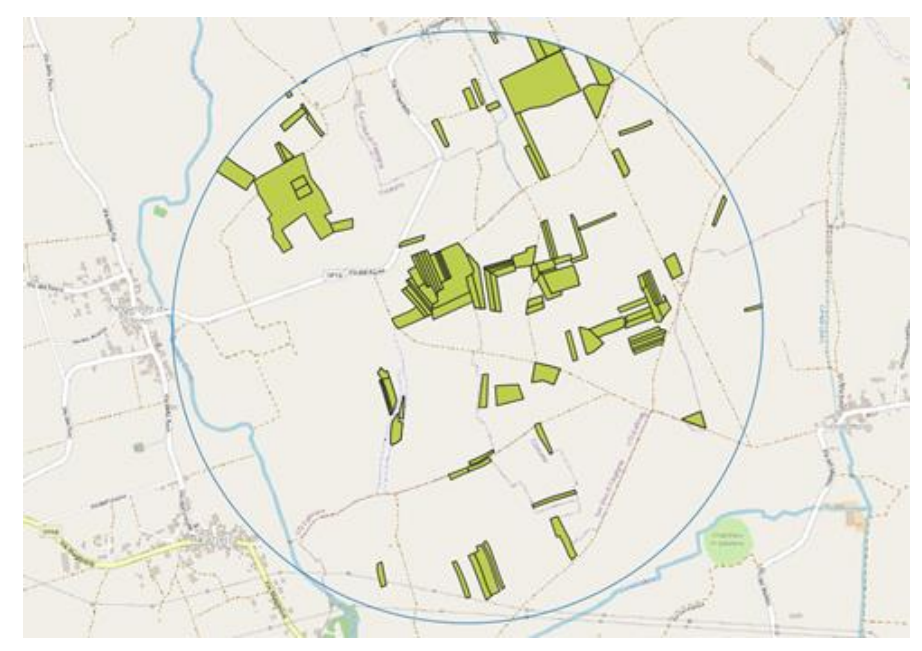

Figure 30. Vectoral representation of the fields declared to be used for conservative agriculture in the study area located in the Plasencis countryside (https://eaglefvg.regione.fvg.it). 
However, the linear and punctual infrastructures within the sample area of the Latisana countryside (Figure 29) only covered 11.2 ha out of a total surface area of 676 ha of agricultural land, in other words $1.7 \%$ of the entire area analysed. Furthermore, the vectoral data made available by IRDAT-FVG showed that there were no fields in the area used for conservative agriculture. The extra-urban green areas in this area is characterised by an agricultural production fabric oriented towards the intensive cropping of seminative plants and shows both a strong vulgarisation of the covering vegetation and the sporadic presence of natural formations.

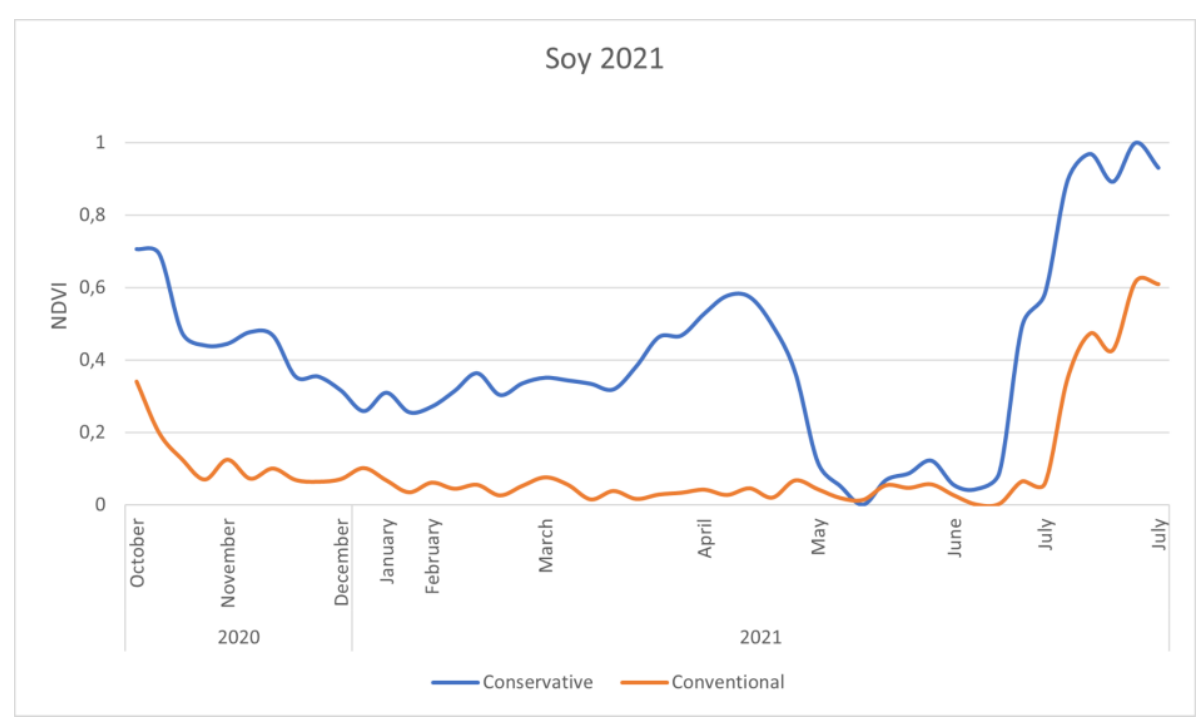

Figure 31. Trends in the standardised NDVI index spectral values on two plots of land: one used for conservative agriculture (Plasencis) and one used for conventional agriculture (Latisana). Soya has been produced in both since June 2021.

Figure 31 shows the trends in the standardised NDVI index spectral values referring to the timeframe from October (2020) to July (2021). The blue line shows the trend in the index of a plot of land used for conservative agriculture in the Plasencis countryside, while the orange line shows that for a plot of land used for conventional agriculture in the Latisana countryside. It can be seen that the NDVI of the plot of land used for conservative agriculture is significantly higher compared to the field used for conventional agriculture for the entire time period taken into consideration. This difference is due to the presence of cover crops in the field used for conservative agriculture, which preserve the fertility of otherwise base soils between one profitable crop and the next, in addition to providing a series of ecosystem services that are vital in terms of maintaining the agricultural ecosystem [30].

The highest NDVI value encountered in the graph for both plots of land in July corresponds to the peak development of the soya plant, a crop which has been present since June 2021 in both plots of land examined. The lowest value of the index in May and June for the conservative agriculture plot represents the time during which the cover crop is removed and the profitable crop is planted. The plot of land used for conventional agriculture shows NDVI index values close to zero for most of the period taken into consideration. This indicates a permanent persistence of bare soil, with all of the related ecological problems [31]. 


\section{Discussion}

The Local Green Plan for Latisana, the Ecopolitana, prefigures a reorganisation that will hopefully drive the overall territorial development of the area, on 4 axes, 2 landscapeenvironmental, one infrastructural and one urban related (the public space), specifically: the agrarian landscape (Especially that of land clearance), the water landscape (rivers, canals and lagoon), slow mobility (cycle lanes such as greenway) and urban green areas (structural connection of the public space in urban centres and the rural hamlets).

Of all of these, perhaps the agricultural matrix is the most important, as it is functional and declinable with regard to the other 3 axes. This leads to the detailed analysis of the recovery of conservative agriculture, and the potential in general of the agricultural environment in the planning of this area, especially as a means of calibration between the urban (small but widespread) and the extra-urban (almost exclusively rural) dimensions In brief, we believe that it is fundamental to analyse in detail the techniques, tools and approach to agriculture in an area that is founded historically on a farming culture, with the settlement principles of the few inhabited centres being a natural evolution in structural terms.

The adoption of agronomic practices aimed at the best possible use of the local resources has over time led to a vulgarisation of the cover crop, the progressive elimination of the traditional agricultural and ecological infrastructures and the reduction of habitats suited to the settlement and reproduction of many species of local wildlife. This has led not only to a significant loss of biodiversity [32] but also to the impoverishment of the quality of the landscape and all of the associated ecosystem services [33][34]. Take for example the cultural, recreational and aesthetic values of the areas bordering the Tagliamento and Stella rivers which were the inspiration for writers, poets and songsters and have now been replaced by a logic of mass production, characterised by large-scale machinery and infinite stretches of bare fields. And also the ecosystem services of regulation, supply and support to life, such as the recycling of nutrients, the purification of water, the sowing of seeds and pollination of plants [35]. Literature is rich in examples of how a connected territorial matrix is absolutely vital in terms of maintaining a healthy ecosystem [36][37][38] and in a context of global change such as the current one its implementation is absolutely necessary. The farming matrix in particular plays a vital role in the environmental functioning of the landscape. This role, which is especially vital in terms of ecological continuity, goes well beyond the reductive concept of "biological corridor" and leads to a reconsideration of the very concept of "ecological network", often intended as merely a green "infrastructure" of the landscape. According to Bennet and Wit (2001) [39] the ecological network is a consistent system of natural and/or semi-natural areas structured and managed with the aim of maintaining or restoring the ecological functions to preserve biodiversity, at the same time creating appropriate opportunities for the sustainable use of natural resources. A farming fabric characterised by natural and semi-natural elements such as single trees, rows of trees, hedges, wooded areas, sheltering woods, ditches and slopes, small ponds, traditional low stone walls and hedged pastures thus highlights very interesting potential for diversifying the landscape, increasing the richness of plant and animal species [40] and restoring dignity to a heavily exploited area such as Latisana.

This has led to the formulation of the Local Green Plan to correct the criticalities identified in the reference LU through the adoption of intervention strategies aimed at improving and enhancing the landscape, the quality of the environment and biodiversity in the area and the proposal of a methodology capable of assisting the authority responsible for monitoring the realisation of the Ecopolitana plan.

In this regard, measuring the density of the agricultural and ecological, linear and punctual infrastructures has proven to be a very interesting landscape ecology index in assessing the structure of the landscape mosaic [41]. This index has enabled attention to 
be focused on aspects that do not generally appear immediately in the perception of a specific landscape, proving itself to be effective both in determining its effective "fragility" and also as a "decision-making support" in making management choices. On the basis of this index, the countryside of Latisana has been shown to be particularly fragile and fragmented [42]. In the sample area in the municipality of Latisana-Precenicco (676 ha), there were less than 12 ha of natural and semi-natural elements capable of connecting the area, compared to 165 ha in the sample area of the countryside in Plasencis (676 ha). Also, the area of Latisana has no fields used for conservative agriculture. This practice is aimed at ensuring stable and sustainable productivity, at the same time preserving and enhancing the agricultural resources and the environment. This is why the choice was made to test an economic and fast tool capable of distinguishing between two systems of farming management, conservative, which is more sustainable, and conventional, in assessing the sustainability of the agricultural matrix. Sentinel-2 images were processed (form October 2020 to July 2021) and the NDVI covering index (reference) tested. It was seen that the comparison between two conservative and conventional plots of land provides positive results in the periods when there is a cover crop, usually from October to May, confirming the results of other studies [43].

From that analysed and in agreement with the goals of the 2030 agenda [44] we have identified conservative practices, combined with integrated fertilization strategies, crop defence and the use of water, as the technical foundations on which to construct a sustainable intensification of agricultural production in the countryside of Latisana. We also believe that it is vital to follow the guidelines suggested in the LGP to construct the ecological network in the same area and encourage biodiversity.

\section{Author Contributions:}

Luca Del Fabbro Machado, Alfredo Altobelli, Jennifer Bertuzzi, Francesca Zampieri e Angela Gatti have developed subsections 1. Introduction, 2. Materials and Methods e 4. Discussion; Adrian Venudo developed subsection 3. Results.

“Conceptualization, L.D.F.M., A.A. and A.V.; methodology, L.D.F.M., A.A. and A.V.; software, L.D.F.M., A.A. and A.V.; validation, L.D.F.M., A.A. and A.V.; formal analysis, A.A.; investigation, L.D.F.M., A.A. and A.V.; resources, L.D.F.M., A.A. and A.V.; data curation, A.A.; writing-original draft preparation, L.D.F.M., A.A. and A.V.; writing - review and editing, L.D.F.M., A.A. and A.V.; visualization, L.D.F.M.; supervision, L.D.F.M.; project administration, L.D.F.M. All authors have read and agreed to the published version of the manuscript."

Funding: This research received no external funding

\section{Data Availability Statement:}

https://www.comune.latisana.ud.it/pcvuee (accessed on 12 August 2021)

Acknowledgments: The autors express their gratitude and appreciation to Latisana municipality.

Conflicts of Interest: Declare conflicts of interest or state "The authors declare no conflict of interest." 


\section{References}

${ }^{1}$ Venudo, A.; Ceschin, E.; Del Fabbro Machado, L. Laboratorio Paesaggio Latisana; EUT, 2020

${ }^{2}$ Ministero dell'ambiente e della tutela del territorio e del mare - Comitato per lo sviluppo del verde pubblico. La strategia per il verde urbano, 2018, from http://www.pubblicigiardini.it/il-comitato-per-il-verde-pubblico-presso-il-ministero-per-lambiente/ (accessed on 12 August 2021)

${ }^{3}$ Ministero dell'ambiente e della tutela del territorio e del mare - Comitato per lo sviluppo del verde pubblico. Linee guida per la gestione del verde urbano e prime indicazioni per una pianificazione sostenibile (Deliberazione 19/2017, del 3 luglio 20217), from http://www.pubblicigiardini.it/il-comitato-per-il-verde-pubblico-presso-il-ministero-per-lambiente/ (accessed on 12 August 2021), p. 15

${ }^{4}$ United Nations. The global goals, from https://www.globalgoals.org/ (accessed on 12 August 2021)

5Power, A. G. Ecosystem services and agriculture: tradeoffs and synergies. Philosophical transactions of the royal society B: biological sciences 365.1554, 2010

'Jeanneret, Ph.; Aviron, S.; Alignier, A.; Lavigne, C.; Helfenstein, J.; Herzog, F.; Kay, S.; Petit, S. . “Agroecology landscapes”. Landscape Ecology 2021, 36, 2235-2257

7Ingegnoli, Vittorio. "Bionomia del paesaggio." Bionomia del paesaggio. Springer, Milano, 2011. 17-43

${ }^{8}$ Friedrich, T., Derpsch, R., Kassam, A. H. ."Global overview of the spread of conservation agriculture”. Field Actions Science Reports, 2012, 6, 1-7

9Sanaullah, M.; Usman, M.; Wakeel, A.; Cheema, S. A.; Ashraf, I.; Farooq, M.. Terrestrial ecosystem functioning affected by agricultural management systems: A review. Soil and Tillage Research, 2020, 196, 104464

${ }^{10}$ Fabbri, P. Principi ecologici per la progettazione del paesaggio, Collana - Il Paesaggio, Franco Angeli, Milano, 2007, p. 29

${ }^{11}$ Ingegnoli, V. Infrastrutture ecologiche e diagnosi dell'ambiente. Il governo dei parchi. Strategie operative per la salvaguardia delle risorse naturali come fattore di miglioramento della qualità della vita e di competitività delle imprese (pp.173-214), Novembre 2019, Aracne Editore, Roma

${ }^{12}$ Rete Rurale Nazionale 2014-2020. Campagna di Plasencis, from https://www.reterurale.it/flex/cm/pages/ServeBLOB.php/L/IT/IDPagina/14367 (accessed on 07 September 2021)

${ }^{13}$ Lucas, Chris, et al. "Identification of linear vegetation elements in a rural landscape using LiDAR point clouds." Remote Sensing 11.3 (2019): 292.

${ }^{14}$ Tucker, C. J. "The NDVI has been proven to be well correlated with various vegetation parameters, such as green biomass." Rouse et al (1979): 605-790.

${ }^{15}$ Forman, R.T.T. et. al. Road Ecology: Science and Solutions; Island Press, Washington DC, 2003

${ }^{16}$ McHarg, Ian L. Design with nature; Doubleday, New York, 1969; p. 191

${ }^{17}$ Opdam, P.; Steingrover, E.; Designing Metropolitan Landscapes for Biodiversity. Deriving guidelines from Metapopulation Ecology. Landscape Journal, 2008, Vol.27, No. 1; p. 69-80

${ }^{18}$ Khoroshev, A. V.; Dyakonov, K. N. Landscape Patterns in a Range of Spatio-Temporal Scales; Springer, Berlin, 2020

${ }^{19}$ Forman individua 5 tipologie/fasi di frammentazione degli habitat delle reti ecologiche: 1) perforation; 2) dissetion; 3) fragmentation; 4) shrinkage; 5) attrition, in Forman, R.T.T. Land mosaics: the ecology of landscapes and regions; Cambridge University Press, United Kingdom, 1995;

${ }^{20}$ Golley, F.B. A history of the ecosystem concept in ecology: more than the sum of the parts; Yale University Press, Newhaven and London: 1994.

${ }^{21}$ Belanger, P. Landscape as infrastructure: a base primer; New York, Routledge, 2017

${ }^{22}$ Corner, J. Landscape Urbanism. Landscape Urbanism a manual for the machinic landscape; London, AA press, 2003

${ }^{23}$ Casini, M. Costruire l'ambiente. Gli strumenti e i metodi della progettazione ambientale; Milano, HOEPLI Edizioni, 2009

${ }^{24}$ Forman, R.T.T. et. al. Road Ecology: Science and Solutions; Island Press, Washington DC, 2003

${ }^{25}$ Forman, R.T.T. Proceedings of the Conference at the Graduated School of Design Harvard College, USA, 2013

${ }^{26}$ Steiner, F. The Living Landscape an Ecological Approach to Landscape Planning; MacGraw-Hill, New York, 1991

${ }^{27}$ RER: Rete Ecologica Regionale prevista dal Piano Paesaggistico Regionale della Regione Friuli-Venezia Giulia, 2018

${ }^{28}$ Fabbri, P. Principi ecologici per la progettazione del paesaggio, Collana - Il Paesaggio, Franco Angeli, Milano, 2007

${ }^{29}$ Waldheim, C. Landscape as urbanism. A general theory, Princeton University Press, Princeton, 2016

${ }^{30} \mathrm{Kim}$, Nakian, et al. "Do cover crops benefit soil microbiome? A meta-analysis of current research." Soil Biology and Biochemistry 142 (2020): 107701.

${ }^{31}$ Delle Vedove, Gemini, and Pierluigi Bonfanti. Agricoltura conservativa in Friuli Venezia Giulia.

${ }^{32} \mathrm{Hanski}$ I. Landscape fragmentation, biodiversity loss and the societal response: The longterm consequences of our use of natural resources may be surprising and unpleasant, EMBO reports 6.5, 2005

${ }^{33}$ Chaplin-Kramer, R. et al. Spatial patterns of agricultural expansion determine impacts on biodiversity and carbon storage, Proceedings of the National Academy of Sciences 112.24, 2015 
${ }^{34}$ Krauss, J., et al. \& Steffan-Derenter, I. Habitat fragmentation causes immediate and time delayed biodiversity loss at different trophic levels, Ecology letters 13.5: 597-605, 2010

${ }^{35}$ Bommarco, R., Vico, G., \& Hallin, S. Exploiting ecosystem services in agriculture for increased food security, Global Food Security, 17, 5763, 2018

${ }^{36}$ Tscharntke, T., et al. Landscape perspectives on agricultural intensification and biodiversity-ecosystem service management, Ecology letters 8.8, 2005

${ }^{37}$ Duflot, R. et al. Reconsidering the role of 'semi-natural habitat'in agricultural landscape biodiversity: a case study, Ecological Research 30.1, 2015

${ }^{38}$ Fahig, L. et al. Functional landscape heterogeneity and animal biodiversity in agricultural ecosystems, Ecology letters 14, 2010

${ }^{39}$ Bennet, G., and P. Wit. "The development and application of ecological networks." A review of Proposals, Plans and Programmes, IUCN (2001).

${ }^{40}$ Veneto Agricoltura. Agroforestazione. Produrre con gli alberi per un'agricoltura differente, from https://www.venetoagricoltura.org/2011/09/editoria/agroforestazione-produrre-con-gli-alberi-per-unagricoltura-differente2011schedae463/

${ }^{41}$ Rete Rurale Nazionale 2014-2020. Individuazione di indici quantitativi e qualitativi e delle fonti informative (banche dati, mappe consultabili) relative alle tecniche di allevamento e architettura degli impianti e dei mosaici paesistici, relativi ai paesaggi rurali storici. Dicembre 2016

${ }^{42}$ Lucas, Chris, et al. "Identification of linear vegetation elements in a rural landscape using LiDAR point clouds." Remote Sensing 11.3 (2019): 292.

${ }^{43} \mathrm{KC}$, Kushal, et al. "Assessment of the Spatial and Temporal Patterns of Cover Crops Using Remote Sensing". Remote Sensing 13.14: (2021):2689.

${ }^{44}$ United Nations. The global goals, from https://www.globalgoals.org/ (accessed on 12 August 2021) 